\title{
Bulky Nature Phenanthroimidazole based Porphyrin Sensitizers for Dye-Sensitized Solar Cell Applications
}

Narra Vamsi Krishna*, Jonnadula Venkata Suman Krishna ${ }^{* *}$, Surya Prakash Singh" Lingamallu Giribabu* ${ }^{*}$, Ashraful Islam ${ }^{*}$, Idriss Bedjal.

'Inorganic \& Physical Chemistry Division, CSIR-Indian Institute of Chemical Technology, Tarnaka, Hyderabad-500007, India.

*Academy of Scientific and Innovative Research, CSIR-Indian Institute of Chemical Technology, India.

${ }^{\S}$ Photovoltaic Materials Unit, National Institute for Materials Science, Sengen 1-2-1, Tsukuba, Ibaraki 3050047, Japan.

'Cornea Research Chair, Department of Optometry, College of Applied Medical Sciences, King Saud University, Riyadh 11433, Saudi Arabia.

Corresponding authors: giribabu@iict.res.in, Phone: +91-40-27191724, Fax: +91-40-27160921; Islam.Ashraful@nims.go.jp,

\begin{abstract}
Porphyrin-based sensitizers have attracted significant attention due to their excellent performance in dye-sensitized solar cells (DSSCs). Herein, a novel electron donor- $\pi$ bridge-electron acceptor $(\mathrm{D}-\pi-\mathrm{A})$ based porphyrin sensitizer having strong electron donating methyl phenanthroimidazole ring and ethynylcarboxyphenyl group at mesoposition of porphyrin framework (LG11) was designed and applied as sensitizer in DSSC. To reduce the undesirable loss of open-circuit voltage $\left(V_{O C}\right)$ caused by dye aggregation and charge recombination effect, phenyl (LG12) or hexyl phenyl chains (LG13 \& LG14) were attached to the phenanthroimidazole moiety. The introduction of a simple thiophene unit between the porphyrin and carboxylic acid anchoring group (LG14) has enabled further extention of the absorption to a longer wavelength. Compared to LG11 and LG12, hexyl phenyl substituted LG13, and LG14 effectively reduced the dye aggregation and allowed enhancement of $V_{O C}$ to $460 \mathrm{mV}$ and $650 \mathrm{mV}$. Both LG13 and LG14 sensitizers exhibit broader and red-shift incident photon conversion efficiency (IPCE) spectra and resulted in highest $J_{S C}$ of 14.2 and $15.5 \mathrm{~mA} \mathrm{~cm}{ }^{-2}$, respectively. Because of all aforesaid properties, LG13 and LG14 dyes show photovoltaic conversion efficiencies of $6.25 \%$ and $7.45 \%$, respectively.
\end{abstract}


Further, a co-sensitization of LG14 with an organic molecule (HC5) to increase the absorption valley in the visible region has seen efficiency enhanced to $8.27 \%$. This work provides a potential approach to molecular design of porphyrin sensitizers and selection of co-sensitizers to build better efficient and stable DSSC system. We have adopted intensitymodulated photo voltage spectroscopy (IMVS) and nanosecond laser flash photolysis spectroscopy to explain the efficiency and structure relationship of these LG11-LG14 sensitizers.

\section{Introduction}

The ever rising energy demand, depletion of fossil fuels and adverse environmental impacts of the fossil fuel based technologies are knocking at the doors of the scientific community to introduce environmentally benign alternative energy conversion systems based on renewable energy sources such as solar cells, electrochemical power sources, etc. ${ }^{1}$ Many researchers are being attracted towards the solar cells mainly dye-sensitized solar cells (DSSCs) due to promising power conversion efficiency (PCE) (crossed certified efficiency of $>11 \%){ }^{2-10}$ and solution processability which allows easy fabricatation on flexible substrate. Despite of all these advantages, the technology is not yet fully commercialized due to technical constrains of various components. The sensitizer is one of the crucial components of the device for achieving its high efficiency and durability. The widely used $\mathrm{Ru}(\mathrm{II})$ polypyridyl complexes have lack of absorption in near-IR region that hinders to further improvement of the device efficiency and also they are expensive due to tedious synthetic and purification protocols. ${ }^{11-15}$ Therefore, judicious selection and/or synthesis of better photosensitizer is a major deciding component of DSSC to achieve higher PCE. In view of this, researchers have made substantial development by adopting the electron donor $-\pi$ bridge-electron acceptor $(\mathrm{D}-\pi-\mathrm{A})$ framework approach for a better design of photosensitizers. ${ }^{16-18}$ To seizure whole visible range, considerable efforts have been focused on the molecular engineering of photosensitizers In this marathon, porphyrins have been found to be the best contenders (thanks to their broad spectral response, high molar extinction coefficient, efficient photo-induced charge transfer, and long- lived charge separated states). ${ }^{19}$ However, the relatively weak light-harvesting ability of porphyrins between the Soret and Q 
band, and in the red region of the solar spectrum is hampering the improvement of DSSC efficiency. Moreover, the $\pi$-interactions between the porphyrin macrocycles lead to the aggregation on the surface of the $\mathrm{TiO}_{2}$, which might affect the further improvement of overall DSSC efficiency.

Therefore, to facilitate better conversion of solar light into energy, dyes should have a lower aggregation tendency, a push-pull structure, and a broad light-harvesting ability. ${ }^{20}$ To get an insight of this, recently, Mathew et. al. reported zinc porphyrin dye SM315, by incorporating a bulky bis(2',4'-bis(hexyloxy)-[1,1'-biphenyl]-4-yl)amine as a donor at mesoposition of porphyrin and 4-(7-ethynylbezo[c][1,2,5]thiadiazol-4-yl)benzoic acid as an acceptor, have obtained a panchormatic porphyrin sensitizer, which showed a PCE of $13 \% .{ }^{21}$ The bulky donor helps to trim down the aggregation and the presence of long alkoxy chain not only improves the solubility but also reduces the charge recombination of the novel sensitizer, and as a result, the PCE is improved. By using a large and a non-planar bulky donor, integrated $\mathrm{D}-\pi-\mathrm{A}$ motif will be a reliable route for designing best porphyrin photosensitizers to build the highly efficient and stable DSSCs. However, the effect of planar and/or non-planar bulky donor incorporated in D- $\pi$-A dyes on their aggregation phenomenon is still matter of debate. For example, bis(2',4'-bis(hexyl oxy)-[1,1'-biphenyl]-4-yl)amine motif in SM315 has shown PCE of $12 \% .{ }^{21}$ Recently, we have carried out a systematic study in D- $\pi$-A approached porphyrin sensitizers in which we have integrated a non-planar butterfly conformational 3-ethynyl-10-octyl-10H-phenothiazine as a donor that reduces the aggregation issue further with varying acceptor moieties and observed PCE of $10.2 \% .^{22}$ In order to further improve the efficiency of the device, one has to introduce more bulky groups like substituted imidazoles group at its meso- position of porphyrin macrocycle. Although there are numerous reports based on imidazole motif in ruthenium and metal free organic dyes, the effect of imidazole units in porphyrin sensitizers is not fully explored ${ }^{11,23,24}$ This approach may help to reduce the aggregation issue somewhat. Another way for further reduction of aggregation and to achieve highly efficient light harvesting system is proper utilization of co-sensitizers with complementary absorption spectra.

Keeping in mind the issue related to the aggregation and charge recombination of photosensitizers, herein, we examine the $\mathrm{D}-\pi-\mathrm{A}$ designed photosensitizers, especially with regards to molecular engineering. Here, we focused on systematic approach by changing the substituents on donor moieties and $\pi$-spacers groups between the porphyrin and carboxylic 


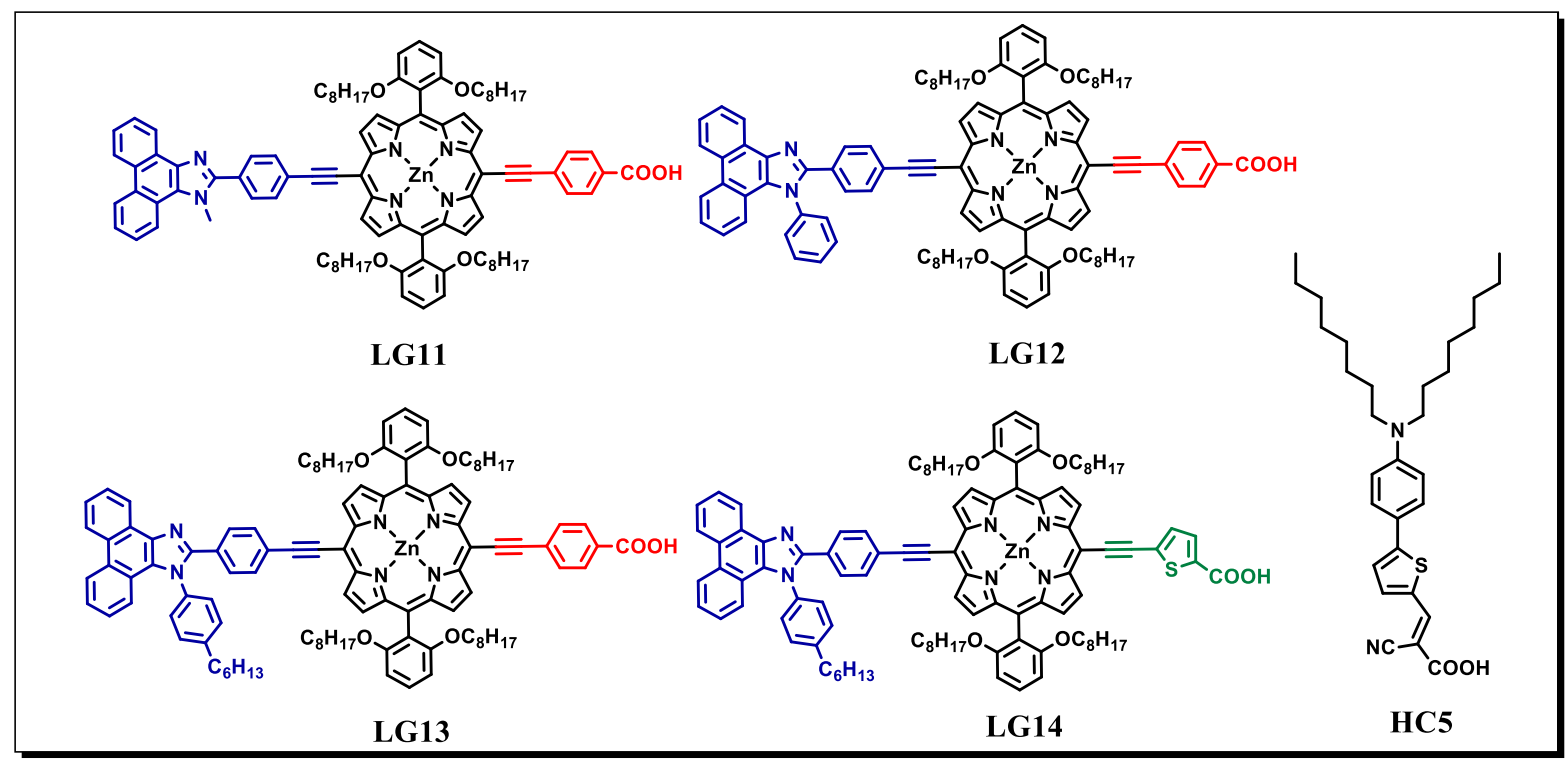

Chart 1. Molecular structures of the porphyrin sensitizers and co-sensitizer.

anchoring groups, expecting as a result, the efficiency of the device may enhance. As shown in chart 1, all four dyes in which the porphyrin moiety mainly shielded with octyloxy groups, which may reduce the charge recombination process between iodine/triiodide moieties and the oxidized dye. Non-planar phenanthroimidazole-based donors with various substituents methyl (LG11), phenyl (LG12), hexyl phenyl (LG13 and LG14) tethered at the mesoposition of the porphyrin ring with ethynyl spacer to investigate the effect of bulky nature electron donor moieties on photovoltaic properties of porphyrins. LG13 and LG14 dyes are having a minor structural difference in the $\pi$-spacers, i.e., phenyl ring in LG13 and thiophene ring in LG14 inserted between the porphyrin and carboxylic anchoring group. This would give a control of $\pi$-spacer groups over the light-harvesting ability of the sensitizers. The substituted phenanthroimidazole porphyrin dyes LG11, LG12, LG13, and LG14 exhibited efficiencies of $3.38 \%, 5.73 \%, 6.25 \%$, and $7.45 \%$, respectively. Furthermore, the N,Ndioctylaminophenyl based co-sensitizer (HC5) has been utilized with LG14 to increase the absorption valley in the visible region and the fabricated device (LG14/HC5) has shown enhanced PCE of $8.27 \%$. Overall, the cocktail of porphyrin, nonplanar and bulky structured hexyl phenyl substituted imidazole donor, light absorbing $\pi$-conjugated system, and cosensitization approaches are efficient and can be used to make future photosensitizes to build better efficient and stable DSSC system.

\section{Experimental section}




\subsection{Materials}

Analytical reagent grade solvents and reagents were used for synthesis, and distilled laboratory grade solvents were used for chromatography. Milli-Q water was used for synthetic and purification purpose. Dichloromethane, chloroform, and acetonitrile were dried in the presence of calcium hydride under nitrogen atmosphere. Hexane, toluene, and tetrahydrofuran were purified by refluxing overnight with $\mathrm{Na}$ metal added benzophenone refluxing overnight, then distilling under a vacuum and storing over $4 \AA$ molecular sieves. Triethylamine was distilled over $\mathrm{NaOH}$ pellets. $\mathrm{N}_{2}$ (oxygen-free) was passed through a $\mathrm{KOH}$ drying column to remove moisture. ACME silica gel (100-200 mesh) was used for column chromatography and thin-layer chromatography was performed on Merck-precoated silica gel $60-\mathrm{F}_{254}$ plates. Either gravity or flash chromatography was used compound purification. Where a dual solvent system was used, gradient elution was employed, and the major band was collected. All porphyrin reactions were carried out under nitrogen or argon atmosphere using dry degassed solvents, and the apparatus was shielded from ambient light.

\subsection{Synthesis}

Phenanthrene-9,10-dione, 4-ethynylbenzaldehyde, methylamine, aniline and 4-hexylaniline, 5-bromothiophene-2-carboxylic acid, 4-iodobenzoic acid, were procured commercially. 2-(4ethynylphenyl)-1-methyl-1H-phenanthro[9,10-d]imidazole(1a), 2-(4-ethynylphenyl)-1phenyl-1H-phenanthro[9,10-d]imidazole(1b), 2-(4-ethynylphenyl)-1-(4-hexylphenyl)-1Hphenanthro[9,10-d]imidazole(1c) ${ }^{21}$ and 5-bromo-15-(Triisopropylsilyl)ethynyl-10,20-bis(2,6di-octoxy phenyl)porphyrinato] Zinc(II) (2) was synthesized as per literature methods. ${ }^{25-27}$ Organic dye N,N-dioctylaminophenyl (HS5) for co-sensitization was synthesized according the procedure reported in the literature. ${ }^{28}$

2.2.1. 2-(4-ethynylphenyl)-1-methyl-1H-phenanthro[9,10-d]imidazole(1a): Phenanthrene9,10-dione (300 mg,1.44mmol), 4-ethynyl benzaldehyde (187.22 $\mathrm{mg}, 1.44 \mathrm{mmol}$ ) and methylamine $(0.07 \mathrm{~mL}, 1.73 \mathrm{mmol})$, ammonium acetate $(554.42 \mathrm{mg}, 7.23 \mathrm{mmol})$ were dissolved in acetic acid $(25 \mathrm{~mL})$ and degassed under sonication. The resulting mixture was stirred under argon at $90^{\circ} \mathrm{C}$ for $24 \mathrm{~h}$. Then the reaction mixture was cooled to rt, solvent was removed under reduced pressure and followed by extraction with dichloromethane solvent. The organic layer was wished with water, dried over $\mathrm{MgSO}_{4}$ and evaporated to dryness under reduced pressure at $50^{\circ} \mathrm{C}$. The obtained residue was purified by silica gel column 
chromatography using (Ethyl acetate $/ \mathrm{n}$-hexanes $=4: 10$, v/v). ${ }^{1} \mathrm{H}$ NMR $(300 \mathrm{MHz}, \mathrm{DMSO}) \delta$ 8.87 (2 H, t, $J$ 9.4), 8.57 (2 H, dd, $J$ 12.6, 7.9), 8.33 (2 H, d, J 8.4), 7.72 (6 H, q, $J 11.9$ ), 4.38 $(1 \mathrm{H}, \mathrm{s}), 3.03$ (3 H, s). HRMS (MALDI-TOF): m/z [M] ${ }^{+}$calcd. for $\mathrm{C}_{24} \mathrm{H}_{16} \mathrm{~N}_{2}, 332.4$; found, 331.9 .

2.2.2. 2-(4-ethynylphenyl)-1-phenyl-1H-phenanthro[9,10-d]imidazole(1b): We have adopted similar procedure as 1a, but only the difference is instead of methylamine, aniline $(0.15 \mathrm{~mL}, 1.73 \mathrm{mmol})$ was taken. The residue was purified by silica gel column chromatography using (Ethyl acetate /n-hexanes $=3: 10$, v/v). ${ }^{1} \mathrm{H} \mathrm{NMR}\left(500 \mathrm{MHz}, \mathrm{CDCl}_{3}\right) \delta$ 8.86 (1 H, dd, J 8.0, 1.1), 8.77 (1 H, d, J 8.2), 8.71 (1 H, d, J 8.3), 7.74 (1 H, d, J 7.0), 7.68 7.60 (5 H, m), 7.56 - $7.51(5 \mathrm{H}, \mathrm{m}), 7.42-7.40(2 \mathrm{H}, \mathrm{m}), 7.19-7.17(1 \mathrm{H}, \mathrm{m}), 3.13(1 \mathrm{H}, \mathrm{s})$. HRMS (MALDI-TOF): m/z [M] ${ }^{+}$calcd. for $\mathrm{C}_{29} \mathrm{H}_{18} \mathrm{~N}_{2}$, 394.4; found, 395.

2.2.3. 2-(4-ethynylphenyl)-1-(4-hexylphenyl)-1H-phenanthro[9,10-d]imidazole(1c): We have adopted similar procedure as 1a, but only the difference is instead of methylamine, 4hexylaniline $(0.33 \mathrm{~mL}, 1.73 \mathrm{mmol})$ was taken. The residue was purified by silica gel column chromatography using (Ethyl acetate /n-hexanes $=2: 10, \mathrm{v} / \mathrm{v}) .{ }^{1} \mathrm{H} \mathrm{NMR}\left(500 \mathrm{MHz}, \mathrm{CDCl}_{3}\right) \delta$ 8.86 - 8.84 (1 H, m), $8.76(1 \mathrm{H}, \mathrm{d}, J$ 8.3), $8.70(1 \mathrm{H}, \mathrm{d}, J$ 8.3), $7.74(1 \mathrm{H}, \mathrm{t}, J 7.3), 7.65$ (1 H, dd, $J$ 11.2, 4.2), 7.56 (2 H, d, J 8.4), 7.50 (1 H, dd, J 11.1, 4.1), 7.41 (1 H, s), 7.39 (6 H, s), 7.22 (1 H, d, J 0.9), $3.12(1 \mathrm{H}, \mathrm{s}), 2.81-2.78(2 \mathrm{H}, \mathrm{m}), 1.76-1.72(2 \mathrm{H}, \mathrm{m}), 1.41-1.36$ (6 $\mathrm{H}, \mathrm{m}), 0.94$ (3H,t,J 6.9). HRMS (MALDI-TOF): m/z [M] ${ }^{+}$calcd. For $\mathrm{C}_{35} \mathrm{H}_{30} \mathrm{~N}_{2}, 478.6$; found, 477.8 .

\subsection{4. [2-(4-ethynylphenyl)-1-methyl-1H-phenanthro[9,10-d]imidazole-15-} (Triisopropylsilyl)ethynyl-10,20-bis(2,6-di-octoxy phenyl)porphyrinato] Zinc(II) (3a):

Compound 2 (200 mg, $0.14 \mathrm{mmol}$ ) and 1a $(96.61 \mathrm{mg}, 0.29 \mathrm{mmol})$ was taken in $30 \mathrm{~mL}$ of dry THF and $5 \mathrm{ml}$ of triethylamine. To this $\mathrm{Pd}\left(\mathrm{PPh}_{3}\right)_{4}(8.4 \mathrm{mg}, 0.007 \mathrm{mmol})$ and $\mathrm{CuI}(1.3 \mathrm{mg}$, $0.007 \mathrm{mmol}$ ) were added and the resultant reaction mixture was stirred at $40^{\circ}$ under an inert atmosphere for $24 \mathrm{~h}$. The completion of the reaction was monitored by TLC. The solvent was removed by rotary evaporation. The residue was purified by silica gel column chromatography $(\mathrm{THF} / \mathrm{n}-\mathrm{hexanes}=1: 10, \mathrm{v} / \mathrm{v})$, (yield 65\%) as green solid. MALDI-TOF: m/z $[\mathrm{M}-\mathrm{H}]^{+}$calcd. for $\mathrm{C}_{99} \mathrm{H}_{118} \mathrm{~N}_{6} \mathrm{O}_{4} \mathrm{SiZn} \%$ 1549.50; found, 1548. ${ }^{1} \mathrm{H}$ NMR $\left(500 \mathrm{MHz}, \mathrm{CDCl}_{3}\right) \delta$ 
9.62 (2 H, d, J 3.5), 9.59 (2 H, d, J 4.4), 8.90 (2 H, d, J 4.3), 8.86 (2 H, s), 7.69 (1 H, s), 7.58 - 7.55 (1 H, m), 7.49 (3 H, dd, J 7.7, 5.2), 7.46 (2 H, d, J 7.9), 7.43 (3 H, s), 7.39(1 H, m), 7.37 (5 H, s), 7.05 (2 H, d, J 7.1), 3.91 (11 H, t, J 5.0), 2.27 (3 H, s), 1.55 (10 H, s), 1.43 (4 H, s), $1.25(10 \mathrm{H}, \mathrm{m}), 1.06-1.00(12 \mathrm{H}, \mathrm{m}), 0.83-0.76(12 \mathrm{H}, \mathrm{m}), 0.52-0.47(30 \mathrm{H}, \mathrm{m})$. FTIR (neat, $\mathrm{cm}^{-1}$ ): 3449, 2926, 2857, 2139, 1697, 1636, 1456, 1385, 1243, 1210, 1094, 1002, $879,769,713,532,463,407$.

\subsection{5. [2-(4-ethynylphenyl)-1-phenyl-1H-phenanthro[9,10-d]imidazole-15-} (Triisopropylsilyl)ethynyl-10,20-bis(2,6-di-octoxy phenyl)porphyrinato] Zinc(II) (3b):

We have adopted similar procedure as $\mathbf{3 a}$, but only the difference is instead of $\mathbf{1 a}, \mathbf{1 b}(114.65$ $\mathrm{mg}, 0.29 \mathrm{mmol}$ ) was taken. The residue was purified by silica gel column chromatography using $(\mathrm{THF} / \mathrm{n}$-hexanes $=1: 10 \mathrm{v} / \mathrm{v})$ solvent mixture, $($ yield $65 \%)$ as green solid. MALDI-TOF: $\mathrm{m} / \mathrm{z}[\mathrm{M}-\mathrm{H}]^{+}$calcd. For $\mathrm{C}_{104} \mathrm{H}_{120} \mathrm{~N}_{6} \mathrm{O}_{4} \mathrm{SiZn} \%$ 1611.57; found, 1611. ${ }^{1} \mathrm{H}$ NMR $(500 \mathrm{MHz}$, $\left.\mathrm{CDCl}_{3}\right) \delta 9.64(2 \mathrm{H}, \mathrm{d}, J 3.2), 8.94(2 \mathrm{H}, \mathrm{d}, J$ 7.9), $8.86-8.84(4 \mathrm{H}, \mathrm{m}), 8.79(2 \mathrm{H}, \mathrm{d}, J$ 8.4), $8.73(2 \mathrm{H}, \mathrm{d}, J$ 8.5), $7.92(2 \mathrm{H}, \mathrm{d}, J$ 8.2), $7.78(2 \mathrm{H}, \mathrm{d}, J$ 7.3), $7.70(4 \mathrm{H}, \mathrm{d}, J 2.7), 7.66(2 \mathrm{H}, \mathrm{s})$, $7.64(2 \mathrm{H}, \mathrm{s}), 7.57$ (1 H, d, J 8.3), 7.52 (2 H, d, J 7.3), 7.28 (2 H, m), 6.98 (2 H, d, J6.8), 3.83 (8 H, t, J 5.4), 2.27 (3 H, s), $1.43(14 \mathrm{H}, \mathrm{s}), 1.24(10 \mathrm{H}, \mathrm{m}), 0.97-0.92(12 \mathrm{H}, \mathrm{m}), 0.79(12 \mathrm{H}$, m), 0.60 (8 H, m), 0.49 (14 H, m), 0.41 (8 H, m).FT-IR(neat, $\left.\mathrm{cm}^{-1}\right): 3422,2924,2856,2139$, $1588,1456,1381,1245,1209,1097,999,836,767,712$.

\subsection{6. [2-(4-ethynylphenyl)-1-(4-hexylphenyl)-1H-phenanthro[9,10-d]imidazole-15- (Triisopropylsilyl)ethynyl-10,20-bis(2,6-di-octoxy phenyl)porphyrinato] Zinc(II) (3c):}

We have adopted similar procedure as 3a, but only the difference is instead of 1a, 1c (118.22 $\mathrm{mg}, 0.29 \mathrm{mmol}$ ) was taken. The residue was purified by silica gel column chromatography using $(\mathrm{THF} / \mathrm{n}$-hexanes $=1: 10, \mathrm{v} / \mathrm{v})$ solvent mixture, (yield 65\%) as green solid. MALDITOF: $\mathrm{m} / \mathrm{z}[\mathrm{M}-\mathrm{H}]^{+}$calcd. for $\mathrm{C}_{110} \mathrm{H}_{132} \mathrm{~N}_{6} \mathrm{O}_{4} \mathrm{SiZn}, 1695.8$; found,1694. ${ }^{1} \mathrm{H}$ NMR (400 MHz, $\left.\mathrm{CDCl}_{3}\right) \delta 9.67$ (4 H, dd, J5.8, 5.2), 8.99 (1H, d, J 7.9), 8.97-8.90 (4 H, dd, J9.7, 6.3), 8.88 (1 H, m), 8.81 (1 H, d, J7.6), 7.91 (2 H, d, J 8.5), 7.81 (3 H, s), 7.80 - 7.71 (4 H, m), 7.56 (2 H, dd, J15.6, 7.2), 7.47 (4 H, m), 7.28 (2 H, d, J 8.6), 6.99 (2 H, d, J 6.1), 3.83 (8 H, t, J 6.5), 2.93 - 2.64 (2 H, m), 2.30 (3 H,s), $1.50(8 \mathrm{H}, \mathrm{s}), 1.48$ - $1.40(17 \mathrm{H}, \mathrm{m}), 1.36(10 \mathrm{H}, \mathrm{m}), 1.01$ 0.89 (14 H, m), 0.78 (10 H, m), $0.68(8 \mathrm{H}, \mathrm{m}), 0.75-0.60$ (14 H, m), 0.58-0.38 (8 H, m). FT-IR (neat, $\mathrm{cm}^{-1}$ ): 3453, 2925, 2855, 1646, 1458, 1383, 1217, 1098, 771. 


\subsection{7. [5,15-bis(2,6-dioctoxyphenyl)-10-(2-(4-ethynylphenyl)-1-methyl-1H-}

phenanthro[9,10-d]imidazole)-20-(4-carboxyphenylethynyl)porphyrinato]

(LG11): To a solution of compound 3a $(200 \mathrm{mg}, 0.13 \mathrm{mmol})$ in an anhydrous THF (20 mL) was added tetrabutyl ammoniumfluoride (TBAF) $(0.6 \mathrm{~mL}, 1 \mathrm{M}$ in THF). The solution was stirred at $0^{\circ} \mathrm{C}$ for $30 \mathrm{~min}$ under inert atmosphere. The mixture was quenched with $\mathrm{H}_{2} \mathrm{O}$ and then extracted with $\mathrm{CH}_{2} \mathrm{Cl}_{2}$. The organic layer was dried over anhydrous $\mathrm{Na}_{2} \mathrm{SO}_{4}$ and the solvent was removed under reduced pressure. The residue (170 $\mathrm{mg}, 0.12 \mathrm{mmol})$ and 4-iodo benzoic acid (145.3 mg, $0.58 \mathrm{mmol})$ were dissolved in a mixture of anhydrous THF $(20 \mathrm{~mL})$ and triehtyl amine $\left(\mathrm{Et}_{3} \mathrm{~N}\right)(8 \mathrm{~mL})$ under nitrogen, then $\mathrm{Pd}_{2}(\mathrm{dba})_{3}(31.3 \mathrm{mg}, 0.03 \mathrm{mmol})$ and $\mathrm{AsPh}_{3}(76.3 \mathrm{mg}, 0.24 \mathrm{mmol})$ were added to the mixture. The solution was refluxed for $17 \mathrm{~h}$. The solvent was removed under reduced pressure. The residue was purified by silica gel column chromatography $\left(\mathrm{CH}_{2} \mathrm{Cl}_{2} / \mathrm{MeOH}=20: 1, \mathrm{v} / \mathrm{v}\right)$, recrystallization from $\mathrm{MeOH} / \mathrm{Ether}$ to give dye LG11 (yield 55\%) as a green solid. Anal. Calcd For $\mathrm{C}_{97} \mathrm{H}_{102} \mathrm{~N}_{6} \mathrm{O}_{6} \mathrm{Zn} \%$ (1513.30): C, 76.99; H, 6.79; N, 5.55. Found: C, 76.94; H, 6.75; N, 5.52. MALDI-TOF: m/z [M+H] calcd. for $\mathrm{C}_{97} \mathrm{H}_{102} \mathrm{~N}_{6} \mathrm{O}_{6} \mathrm{Zn}, 1513.30$; found,1514. ${ }^{1} \mathrm{H}$ NMR (300 MHz, $\mathrm{CDCl}_{3}+$ pyridine-d $\left.\mathrm{d}_{5}\right) \delta$ 9.64 (2 H, d, J 4.6), 9.61 (2 H, d, J 4.6), 8.99 (2 H, d, J 10.3), 8.89 (4 H, d, J 3.1), 8.82 - 8.78 $(2 \mathrm{H}, \mathrm{m}), 8.75$ (2 H, d, J 7.7), 8.33 (2 H, s), 8.04 (2 H, s), 7.87 (2 H, d, J 8.4), 7.80 (2 H, s), $7.77(2 \mathrm{H}, \mathrm{m}), 7.71(2 \mathrm{H}, \mathrm{s}), 7.29(2 \mathrm{H}, \mathrm{s}), 7.05(2 \mathrm{H}, \mathrm{d}, J$ 6.5), $3.89(11 \mathrm{H}, \mathrm{t}, J$ 6.3), 1.40 (7 H, m), $1.27(6 \mathrm{H}, \mathrm{s}), 0.93(12 \mathrm{H}, \mathrm{m}), 0.72(7 \mathrm{H}, \mathrm{s}), 0.60(4 \mathrm{H}, \mathrm{s}), 0.58(8 \mathrm{H}, \mathrm{m}), 0.56(8 \mathrm{H}, \mathrm{m})$, 0.44 (8 H, m).FT-IR (neat, $\mathrm{cm}^{-1}$ ): 3422, 3055, 2921, 2851, 2182, 1586, 1519, 1455, 1381, 1337, 1246, 1173, 1094, 995, 841, 790, 720, 691, 538, 465, 406.

\subsection{8. [5,15-bis(2,6-dioctoxyphenyl)-10-(2-(4-ethynylphenyl)-1-phenyl-1H-} phenanthro[9,10-d]imidazole)-20-(4-carboxyphenylethynyl)porphyrinato]

Zinc(II)

(LG12): We have adopted similar procedure as LG11, but only the difference is instead of 3a, 3b (200 mg, $0.12 \mathrm{mmol})$ was taken. To the residue (170 mg, $0.11 \mathrm{mmol})$ and 4-iodo benzoic acid (139 mg, $0.56 \mathrm{mmol}), \mathrm{Pd}_{2}(\mathrm{dba})_{3}(29.93 \mathrm{mg}, 0.032 \mathrm{mmol})$ and $\mathrm{AsPh}_{3}(72.9 \mathrm{mg}$, $0.24 \mathrm{mmol}$ ) were added. The residue was purified by silica gel column chromatography $\left(\mathrm{CH}_{2} \mathrm{Cl}_{2} / \mathrm{MeOH}=20: 1, \mathrm{v} / \mathrm{v}\right)$, recrystallization from $\mathrm{MeOH} / \mathrm{Ether}$ to give dye LG12 (yield $55 \%$ ) as a green solid. Anal. Calcd For $\mathrm{C}_{102} \mathrm{H}_{104} \mathrm{~N}_{6} \mathrm{O}_{6} \mathrm{Zn} \%$ (1575.37): C, 77.77; H, 6.65; N, 5.33. Found: $\mathrm{C}, 77.74 ; \mathrm{H}, 6.61 ; \mathrm{N}$, 5.32. MALDI-TOF: $\mathrm{m} / \mathrm{z}[\mathrm{M}-\mathrm{H}]^{+}$calcd. for $\mathrm{C}_{102} \mathrm{H}_{104} \mathrm{~N}_{6} \mathrm{O}_{6} \mathrm{Zn}, 1575.37$; found, 1575. ${ }^{1} \mathrm{H}$ NMR (300 MHz, $\mathrm{CDCl}_{3}+$ pyridine-d $\left.\mathrm{d}_{5}\right) \delta 9.66(2 \mathrm{H}$, d, $J$ 4.4), 9.63 (2 H, d, J 4.0), 9.02 (2 H, d, J 4.9), 8.92 (4 H, t, $J 4.7), 8.80$ (2 H, d, J 7.9), 
$8.74(2 \mathrm{H}, \mathrm{d}, J$ 7.7), $8.35(2 \mathrm{H}, \mathrm{d}, J$ 7.2), $8.03(2 \mathrm{H}, \mathrm{d}, J$ 8.2), $7.89(2 \mathrm{H}, \mathrm{d}, J$ 8.4), $7.80(2 \mathrm{H}, \mathrm{s})$, $7.78-7.76(2 \mathrm{H}, \mathrm{m}), 7.73(2 \mathrm{H}, \mathrm{s}), 7.63(4 \mathrm{H}, \mathrm{s}), 7.48(1 \mathrm{H}, \mathrm{s}), 7.28(2 \mathrm{H}, \mathrm{d}, J 3.4), 7.06(2 \mathrm{H}$, d, $J$ 6.7), 3.89 (8 H, t, J 6.4), 1.27 (4 H, s), 0.96 - 0.89 (18 H, m), 0.72 (8 H, dd, J 12.1, 2.9), $0.61-0.56(22 \mathrm{H}, \mathrm{m}), 0.47-0.42(8 \mathrm{H}, \mathrm{m})$. FT-IR (neat, $\left.\mathrm{cm}^{-1}\right): 3444,2922,2852,2186$, 1681, 1599, 1500, 1454, 1418, 1382, 1246, 1203, 1166, 1095, 997, 938, 829, 789, 713, 459, 403.

\subsection{9. [5,15-bis(2,6-dioctoxyphenyl)-10-(2-(4-ethynylphenyl)-1-(4-hexylphenyl)-1H-} phenanthro[9,10-d]imidazole)-20-(4-carboxyphenylethynyl)porphyrinato]Zinc(II)) (LG13): We have adopted similar procedure as LG11, but only the difference is instead of 3a, 3c (196.2 mg, $0.58 \mathrm{mmol})$ was taken. To the residue $(170 \mathrm{mg}, 0.11 \mathrm{mmol})$ and 4-iodo benzoic acid (131.3 mg, $0.53 \mathrm{mmol}), \mathrm{Pd}_{2}(\mathrm{dba})_{3}(28.28 \mathrm{mg}, 0.030 \mathrm{mmol})$ and $\mathrm{AsPh}_{3}(68.9 \mathrm{mg}$, $0.22 \mathrm{mmol}$ ) were added. The residue was purified by silica gel column chromatography $\left(\mathrm{CH}_{2} \mathrm{Cl}_{2} / \mathrm{MeOH}=20: 1, \mathrm{v} / \mathrm{v}\right)$, recrystallization from $\mathrm{MeOH} / \mathrm{Ether}$ to give dye LG13 (yield $55 \%$ ) as a green solid. Anal. Calcd For $\mathrm{C}_{108} \mathrm{H}_{116} \mathrm{~N}_{6} \mathrm{O}_{6} \mathrm{Zn} \%$ (1659.53): C, 78.17; H, 7.05; N, 5.06. Found: C, 78.20; H, 7.01; N, 5.02. MALDI-TOF: $\mathrm{m} / \mathrm{z}[\mathrm{M}-\mathrm{H}]^{+}$calcd. For $\mathrm{C}_{108} \mathrm{H}_{116} \mathrm{~N}_{6} \mathrm{O}_{6} \mathrm{Zn}, 1659.53$, found,1658. ${ }^{1} \mathrm{H}$ NMR (300 MHz, $\mathrm{CDCl}_{3}+$ pyridine-d $\left.\mathrm{d}_{5}\right) \delta 9.64(2$ H, d, J 4.6), 9.61 (2 H, d, J 4.6), 9.00 (2 H, d, J 8.1), 8.89 (4 H, s), 8.79 (2 H, d, J 6.4), 8.74 (2 H, d, J 7.9), 8.33 (2 H, d, J 7.4), 8.04 (2 H, d, J 7.8), 7.87 (2 H, s), 7.79 (4 H, s), 7.74 (2 H, s), 7.46 (4 H, s), 7.29 (2 H, s), 7.05 (2 H, d, J 6.9), 3.89 (8 H, t, J 6.1), 2.82 (2 H, s), 1.40 (5 H, s), $1.27(6 \mathrm{H}, \mathrm{s}), 0.92(22 \mathrm{H}, \mathrm{d}, J$ 7.4), $0.71(8 \mathrm{H}, \mathrm{d}, J 3.2), 0.58(22 \mathrm{H}, \mathrm{s}), 0.46-0.42(8 \mathrm{H}$, m).FT-IR (neat, $\mathrm{cm}^{-1}$ ): 3419, 2921, 2852, 2186, 1682, 1597, 1505, 1453, 1381, 1338, 1246, $1204,1170,1094,996,834,791,716,469$.

\subsubsection{0. [5,15-bis(2,6-dioctoxyphenyl)-10-(2-(4-ethynylphenyl)-1-(4-hexylphenyl)-1H-} phenanthro[9,10-d]imidazole)-20-(2-carboxythiophene-5-ethynyl)porphyrinato]Zinc(II)

(LG14): We have adopted similar procedure as LG13, but only the difference is instead of 4iodo benzoic acid, 5-bromothiophene-2-carboxylic acid (109.63 $\mathrm{mg}, 0.53 \mathrm{mmol}$ ) was taken. The residue was purified by silica gel column chromatography $\left(\mathrm{CH}_{2} \mathrm{Cl}_{2} / \mathrm{MeOH}=20: 1\right.$, v/v), recrystallization from $\mathrm{MeOH} /$ Ether to give dye LG14 (yield 55\%) as a green solid. Anal. Calcd For $\mathrm{C}_{106} \mathrm{H}_{114} \mathrm{~N}_{6} \mathrm{O}_{6} \mathrm{SZn} \%$ (1655.55): C, 76.44; H, 6.90; N, 5.05. Found: C, 76.40; H, 6.96; N, 5.02. MALDI-TOF: m/z [M-H] $]^{+}$calcd. for $\mathrm{C}_{106} \mathrm{H}_{114} \mathrm{~N}_{6} \mathrm{O}_{6} \mathrm{SZn}, 1665.55$, found, 1664 . ${ }^{1} \mathrm{H}$ NMR (300 MHz, $\mathrm{CDCl}_{3}+$ pyridine-d $\left._{5}\right) \delta 9.39$ (2 H, d, J 4.6), 9.31 (2 H, d, J 4.5), 8.68 - 
$8.60(4 \mathrm{H}, \mathrm{m}), 8.07(2 \mathrm{H}, \mathrm{d}, J$ 8.1), $7.84(1 \mathrm{H}, \mathrm{d}, J$ 8.3), $7.75(1 \mathrm{H}, \mathrm{s}), 7.67(1 \mathrm{H}, \mathrm{s}), 7.62(1 \mathrm{H}$, s), $7.58(2 \mathrm{H}, \mathrm{d}, J 6.7), 7.53(1 \mathrm{H}, \mathrm{s}), 7.46(3 \mathrm{H}, \mathrm{d}, J$ 8.2), $7.21(1 \mathrm{H}, \mathrm{s}), 7.12-7.10(1 \mathrm{H}, \mathrm{m})$, 7.04 ( $2 \mathrm{H}, \mathrm{d}, J$ 4.6), $7.02-6.97$ (4 H, m), $6.92-6.86$ (2 H, m), 6.78 (2 H, d, J 7.2), 3.63 (8 H, t, J 6.1), 2.84 (2 H, s), $1.53-1.47$ (2 H, m), $1.09-0.93$ (9 H, m), 0.64 (22 H, dd, J 15.0, 7.7), $0.46-0.37$ (8 H, m), 0.29 (22 H, d, J 7.4), 0.17 (8 H, d, J 5.6). FT-IR (neat, $\mathrm{cm}^{-1}$ ): 3424, 2921, 2851, 2181, 1604, 1516, 1494, 1454, 1382, 1245, 1202, 1095, 994, 840, 789, 719, 692, $539,470$.

\subsection{Methods and Instrumentation:}

${ }^{1} \mathrm{H}$ NMR spectra were obtained at $300 \mathrm{MHz}$ using a Brucker 300 Avance NMR spectrometer running X-WIN NMR software. The chemical shifts are relative to tetramethylsilane (TMS). The Fourier transform IR (FTIR) spectra of all the samples were measured using a Thermo Nicolet Nexus 670 spectrometer. Cyclic- and differential pulse voltammetric measurements were performed on a PC-controlled $\mathrm{CH}$ instruments model $\mathrm{CHI}$ 620C electrochemical analyzer. Cyclic voltammetric experiments were performed on $1 \mathrm{mM}$ porphyrin dyads solution in dichloromethane at scan rate of $100 \mathrm{mV} / \mathrm{s}$ using $0.1 \mathrm{M}$ tetrabutyl ammoniumhexafluorophosphate $\left(\mathrm{TBAPF}_{6}\right)$ as supporting electrolyte. The working electrode is glassy carbon, standard calomel electrode (SCE) is reference electrode and plantinum wire is an auxillary electrode. After a cyclic voltammogram $(\mathrm{CV})$ had been recorded, ferrocene was added, and a second voltammogram was measured. Spectroelectrochemical experiments were performed using a $\mathrm{CH}$ instruments model $\mathrm{CHI}$ 620C electrochemical analyzer utilizing a three-electrode configuration of thin layer quartz spectroelectrochemical cell at $25{ }^{\circ} \mathrm{C}$. The working electrode was transparent Pt gauze. Pt wire counter electrode and SCE reference electrode separated from the bulk of the solution by a double bridge were used. MALDI-MS spectra were recorded on a TO-4X KOMPACT SEQ, KARTOS, UK, mass spectrometer. Major fragmentations are given as percentages relative to the base peak intensity. Thermogravimetric measurements were carried out on a Mettler Toledo TGA/SDTA 851e instrument heating rate at $10{ }^{\circ} \mathrm{C} \mathrm{min}-1$ with $10 \mathrm{mg}$ of sample.

2.3.1. Absorption steady state and time resolved fluorescence measurements. The UV-Visible spectra were recorded with a Shimadzu (Model UV-3600) spectrophotometer for 1 X $10^{-6} \mathrm{M}$ (porphyrin Soret band) and $5 \times 10^{-5} \mathrm{M}$ (porphyrin Q bands) solutions. Steady state 
fluorescence spectra were recorded using a Spex model Fluoromax-3 spectrofluorometer for solutions having optical density at the wavelength of excitation $\left(\lambda_{\mathrm{ex}}\right) \approx 0.2$. The fluorescence quantum yields $(\phi)$ were estimated by integrating the fluorescence bands and by using 5,10,15,20-tetraphenylporphyrinatozinc(II) ([ZnTPP]) $\left(\phi=0.036\right.$ in $\left.\mathrm{CH}_{2} \mathrm{Cl}_{2}\right)$ as the standards. ${ }^{29}$ Time-resolved fluorescence measurements have been carried out using HORIBA Jobin Yvon spectrofluorometer. The samples were excited at $650 \mathrm{~nm}$ and the emission was monitored at $680 \mathrm{~nm}$. The count rates employed were typically $10^{3}-10^{4} \mathrm{~s}^{-1}$. Deconvolution of the data was carried out by the method of iterative reconvolution of the instrument response function and the assumed decay function using DAS-6 software. The goodness of the fit of the experimental data to the assumed decay function was judged by the standard statistical tests.

\subsubsection{Theoretical Calculations:}

Full geometryboptimization confirmed to be genuine global minimum structures of the sensitizers LG11-LG14 was carriedout with the DFT studies, and B3LYP method using 6$31 \mathrm{G}(\mathrm{d}, \mathrm{p})$ basis set $\mathrm{t}^{30,31}$ by Gaussian09 (RevisionB.01) ab initio quantum chemical software ${ }^{32}$ in the personal computer. Density Functional Theory (DFT) was used to determine the ground state properties in gas phase, while time dependent-DFT(TD-DFT) was employed for estimation of ground state to excited state transitions by B3LYP and 6-31G(d,p) basis set. The geometries were used to obtain the frontier molecular orbitals (FMOs) and were also subjected to single-point TDDFT studies to obtain the UV-vis spectra of the dyes. The integral equation formalism polarizable continuummodel (PCM) within the self-consistent reaction field (SCRF) theory was used in the TDDFT calculations to describe the solvation of the dyes in tetrahydrofuran. ${ }^{33,34}$ The software GaussSum 2.2.5 was employed to simulate the major portions of the absorption spectra and to interpret the nature of transitions. ${ }^{35,36}$ The contribution percentages of individual units present in the dyes to the respective molecular orbitals were calculated.

\subsubsection{Device fabrication.}

$\mathrm{TiO}_{2}$ photoelectrode was prepared by a similar method reported in the literature. ${ }^{37,38}$ The $\mathrm{TiO}_{2}$ paste (approximately $20 \mathrm{~nm}$ in diameter) was first screen-printed on fluorine doped $\mathrm{SnO}_{2}$ conducting glass (transmission $>85 \%$ in the visible, sheet resistance $10 \Omega$ /square) to form a 
transparent layer (cell area is $0.25 \mathrm{~cm}^{2}$ ) of $8 \mu \mathrm{m}$ in thickness. Subsequently, a second scattering layer made up of a paste containing $400 \mathrm{~nm}$ anatase $\mathrm{TiO}_{2}$ particles $5 \mu \mathrm{m}$ in thickness was prepared. Last, screen-printed double-layer film was heated to $500{ }^{\circ} \mathrm{C}$ in an oxygen atmosphere for $1 \mathrm{~h}$. Thickness of the films was measured with a Surfcom 1400A surface profiler (Tokyo Seimitsu Co. Ltd.). The dye was dissolved in 1:1 (v/v) acetonitrile/tert-butyl alcohol at a concentration of $0.2 \times 10^{-3} \mathrm{M}$. The $\mathrm{TiO}_{2}$ thin films were soaked in the dye solution and then kept at room temperature for $15 \mathrm{~h}$ so that the dye was adsorbed onto $\mathrm{TiO}_{2}$ films. The dye coating was done immediately after the high temperature annealing in order to avoid rehydration of the $\mathrm{TiO}_{2}$ surface or capillary condensation of water vapors from ambient air inside the nanopores of the film. The presence of water in the pores decreases the injection efficiency of the dye. The electrode was dipped into the dye solution while it was still hot, i.e., its temperature was ca. $80{ }^{\circ} \mathrm{C}$. After completion of the dye adsorption, the photoelectrode was withdrawn from the solution and washed thoroughly with acetonitrile to remove non-adsorbed dye under a stream of dry air or argon. To assemble each cell, each dye-coated $\mathrm{TiO}_{2}$ film and a platinum-coated conducting glass were separated by a Surlyn spacer $\left(40 \mu \mathrm{m}\right.$ thick) and sealed by heating the polymer frame at $100{ }^{\circ} \mathrm{C}$. An electrolyte consisting of a mixture of $0.6 \mathrm{M}$ dimethylpropyl-imidazolium iodide, $0.05 \mathrm{M} \mathrm{I}_{2}$, 0.1M LiI, and 0.5 M tert-butylpyridine in acetonitrile was used in each cell. The currentvoltage characteristics were measured using a black metal mask with an area of $0.25 \mathrm{~cm}^{2}$ under A M 1.5 sunlight (100 mW cm${ }^{-2}$, WXS-155S-10: Wacom Denso Co. Japan). The incident photon-to-current conversion efficiency (IPCE) spectra were measured with a monochromatic incident light of $1 \times 10^{16}$ photons $\mathrm{cm}^{-2}$ in direct current mode (CEP-2000BX, Bunko-Keiki).

\subsubsection{Transient Absorption Spectroscopy.}

A laser flash photolysis spectrometer (model LP920, Edinburg) has been used. It was associated with a Continuum Nd:YAG laser (Surelite; $10 \mathrm{~Hz}$ repetition rate; fwhm $5 \mathrm{~ns}$ ). A Surelite optical parametric oscillator permits conversion of the second harmonic to a visible spectrum 400-820 $\mathrm{nm}$. The respective dyes were excited at $445 \mathrm{~nm}$. The excited state decay of the dye and the recovery of its fundamental state were monitored by the change in the absorbed continuous wave light. A satisfactory signal-to-noise ratio was obtained by averaging absorption spectra for 100-200 laser shots. 


\subsubsection{CEM and IMVS measurements.}

The photovoltaic response induced by the modulated light was studied by using intensitymodulated photo voltage spectroscopy (IMVS). A potentiostat (Solartron1287) equipped with a frequency response analyzer (Solartron1255B) at an open-circuit condition, based on a monochromatic illumination $(420 \mathrm{~nm})$ controlled by Lab view system was used to measure IMVS. The modulated light was driven with a $10 \% \mathrm{AC}$ perturbation current superimposed on a DC current in a frequency range from 0.1 to $106 \mathrm{~Hz}$. The charge extraction method (CEM) was performed with the same monochromatic light source. The solar cell was illuminated at an open-circuit condition for $5 \mathrm{~s}$ to attain a steady state and then the light source was switched off when the device simultaneously switched to a short-circuit condition to extract the charges generated at that light intensity.

\section{Results and discussion.}

3.1. Synthesis. Synthetic scheme of all four novel porphyrin sensitizers are illustrated in Scheme 1 . The compounds $1 \mathrm{a}, \mathrm{b}, 1 \mathrm{c} \& 2$ were synthesized by adopting procedure reported elsewhere in literature. ${ }^{23-26}$ The compounds $1 \mathrm{a}, 1 \mathrm{~b}$, and $1 \mathrm{c}$ reacted with compound 2 by Sonogashira coupling reaction which gives the intermediates $3 \mathrm{a}, 3 \mathrm{~b}$, and $3 \mathrm{c}$, respectively (Scheme 1). ${ }^{39}$ Subsequently, 3a, 3b and 3c were deprotected and further coupling reaction was carried with respective bromo aromatic acids by using $\mathrm{AsPh}_{3}$ and $\mathrm{Pd}_{2}(\mathrm{dba})_{3}$ reagents. Finally, the desired sensitizers were obtained by silica gel column chromatography purification (Scheme 1). All above sensitizers were fully characterized by elemental analyses, MALDI-TOF-MS, ${ }^{1} \mathrm{H}$ NMR, IR, UV-Visible, fluorescence spectroscopic techniques as well as electrochemical methods. The elemental analyses of all four sensitizers are found to be satisfactory (See experimental section). The mass spectral data of all these sensitizers are having molecular ion peak to their corresponding molecular weight confirming the presence of respective sensitizer (See Supporting Information Figure S1-S20). 


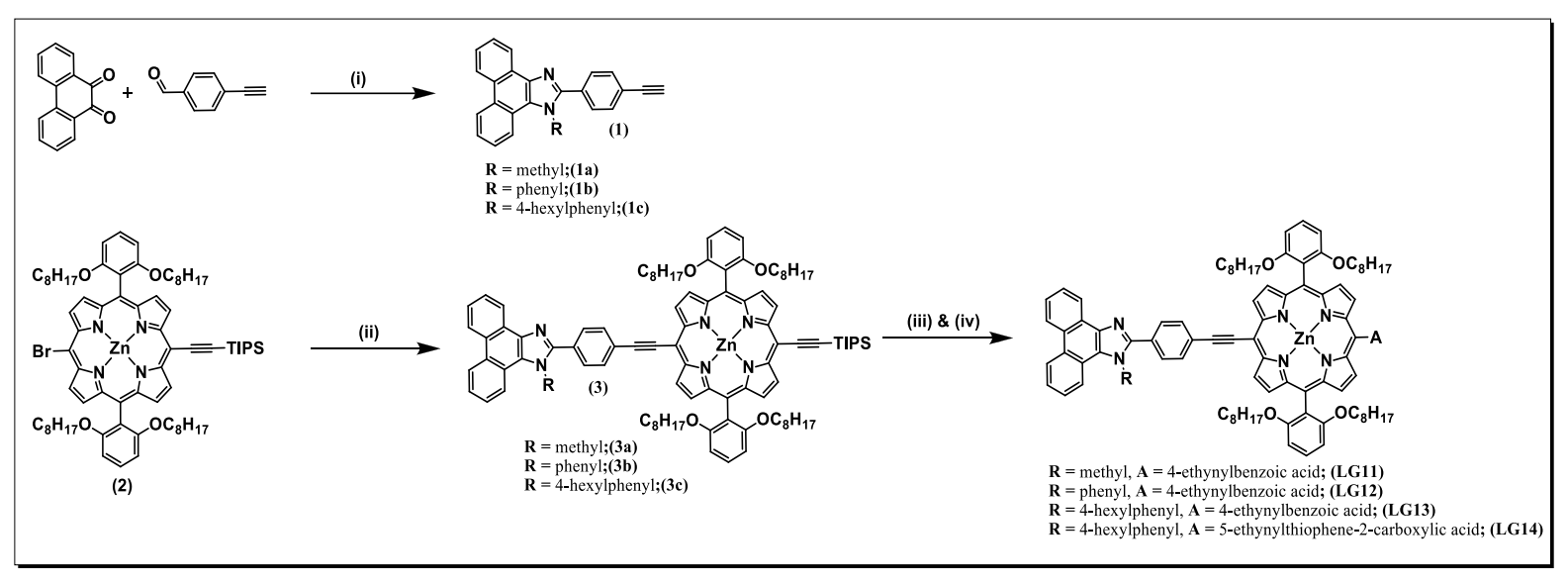

Scheme 1: Synthetic route for compounds (LG11-14). Reaction conditions: (i) $\mathrm{CH}_{3} \mathrm{CO}_{2} \mathrm{NH}_{4}$, $\mathrm{CH}_{3} \mathrm{COOH}, \mathrm{R}-\mathrm{NH}_{2}, 90^{\circ} \mathrm{C}, 24 \mathrm{~h}$. (ii) 1, $\mathrm{Pd}\left(\mathrm{PPh}_{3}\right)_{4}, \mathrm{CuI}, \mathrm{THF}, \mathrm{Et}_{3} \mathrm{~N}, 40^{\circ} \mathrm{C}, 5 \mathrm{~h}$, (iii) $\mathrm{TBAF}$, THF, $0^{\circ} \mathrm{C}$, 30min; (iv) $\left(\mathrm{Pd}_{2}(\mathrm{dba})_{3}, \mathrm{AsPh}_{3}\right.$, THF, Et $3 \mathrm{~N}$, reflux, $17 \mathrm{~h}$.

3.2. Optical properties: The optical properties of newly synthesized sensitizers were measured in THF solvent and the representative absorption spectra of LG13 \& LG14 were depicted in Figure 1. The corresponding wavelength of absorption maxima $\left(\lambda_{\max }\right)$ and logarithmic of molar extinction coefficients $(\varepsilon)$ of LG11-LG14 are given in Table 1. From Figure 1 and Table 1, we may conclude that all four metallo porphyrins exhibit an intense Soret band at around $450 \mathrm{~nm}$, which is an $\mathrm{a}_{1 \mathrm{u}}(\pi) / \mathrm{e}_{\mathrm{g}}\left(\pi^{*}\right)$ electronic transition, assigned to the second excited state (S2), and two less intense Q bands (550-750 nm) originated from the $\mathrm{a}_{2 \mathrm{u}}(\pi) / \mathrm{e}_{\mathrm{g}}\left(\pi^{*}\right)$ electronic transition, attributed to the first excited state (S1). The Soret and Q band absorption maxima of LG11, LG12, LG13 \& LG14 are found at 458, 457, 458, \& 460 $\mathrm{nm}$ and at 670,662, 663, and $667 \mathrm{~nm}$, respectively. The broadening and the enhancing the $\varepsilon$ values of present sensitizers, when compared to 5,10,15,20-(tetra phenyl)porphyrinato zinc(II) (ZnTPP), are due to the elongation of $\pi$-conjugation and non-planarity in porphyrins. ${ }^{40}$ In addition to this, we found the slight red-shift in both Soret and Q band absorption of LG13 \& LG14 in comparison to LG12, which could be due to the symmetry loss affected by the furnishing of hexyl phenyl substitution. Furthermore, the insertion of the thiophene $\pi$-conjugated ring into LG14 dramatically red-shifted the $\lambda_{\max }$ of the $\mathrm{Q}$ band, similar to that observed for LG2 and LG5 of our previously reported sensitizers. ${ }^{22}$ On the other hand, the more planar LG11 porphyrin is found to be aggregated which might result into the broadening of Soret and $\mathrm{Q}$ bands and attained a significant onset absorption wavelength of $750 \mathrm{~nm}$. Also illustrated in Figure 1 are the simulated absorption spectra of LG13 \& LG14 obtained from TDDFT calculations. Additionally, the optical study was done 
on coated LG11-LG14 sensitizers on the surface of $\mathrm{TiO}_{2}$ film $\left(\mathrm{TiO}_{2}\right.$ film thickness is $\left.3 \mu \mathrm{m}\right)$ (see results in Figure 2a). The absorption spectra of all sensitizers have shown a valley in $500-550 \mathrm{~nm}$ region and therefore co-sensitization of an organic molecule having absorption in this region may enhance not only the absorption but also the overall efficiency of the device. We have used N,N-dioctylaminophenyl (HS5) as a co-sensitizer which shows an absorption onset up to $600 \mathrm{~nm}$ in in 1:1 $\mathrm{ACN}$ and $\mathrm{BuOH}$ solution. Figure $2 \mathrm{~b}$ illustrates the absorption spectra of HC5 as well as LG14 + HC5 when adsorbed on $\mathrm{TiO}_{2}$. From the Figure $2 b$ it suggests that the co-sensitizer fill valley between the Soret and Q bands of LG14 sensitizer, which covers absorption spectra from 450-700nm region, which is beneficial for wide range of light-harvesting ability and will effect on $J_{S C}$

The emission spectra of all four D- $\pi$-A porphyrin sensitizers were measured at room temperature in THF solvent, and the representative emission spectra of LG13 \& LG14 are illustrated in Figure 1, with the corresponding emission maxima and quantum yields reported in Table 1. From Table 1, it suggests that the quantum yields of all four sensitizers are enhanced in comparison with reference compound ZnTPP. ${ }^{41}$ Also it suggests that the trend in red-shift emission is similar to the trend of their $\mathrm{Q}$ band absorption spectra. The emission maxima of LG14 show a further red-shifted when compared to LG13 A similar feature was also observed in other porphyrin-thiophene conjugates which indicate that the electronic

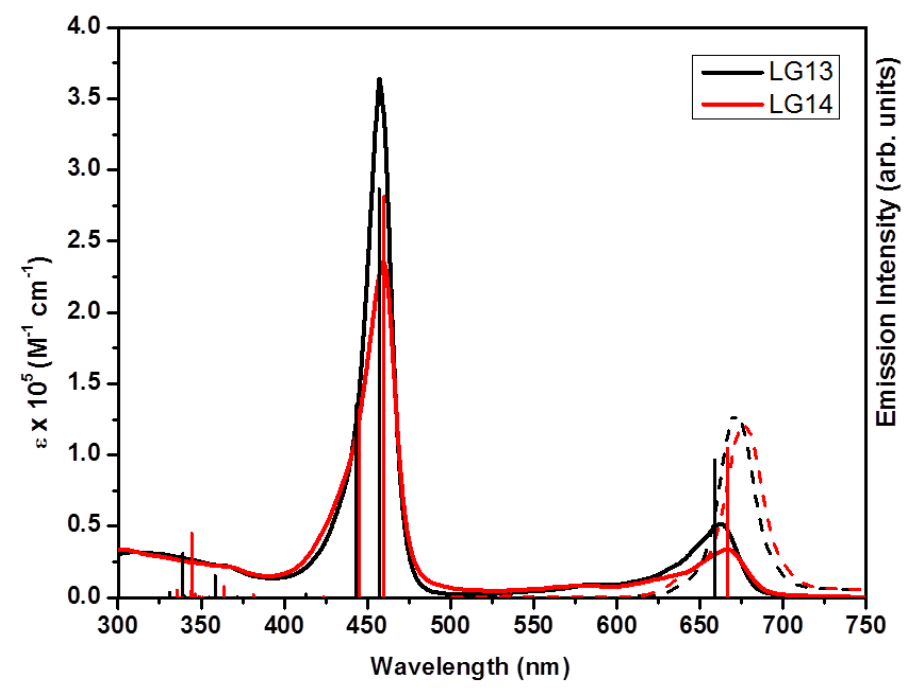

Figure 1: Absorption (left) and emission (right) spectra of porphyrin sensitizers LG13 and LG14 in the THF solvent. Simulated absorption bands are shown as vertical bars. 

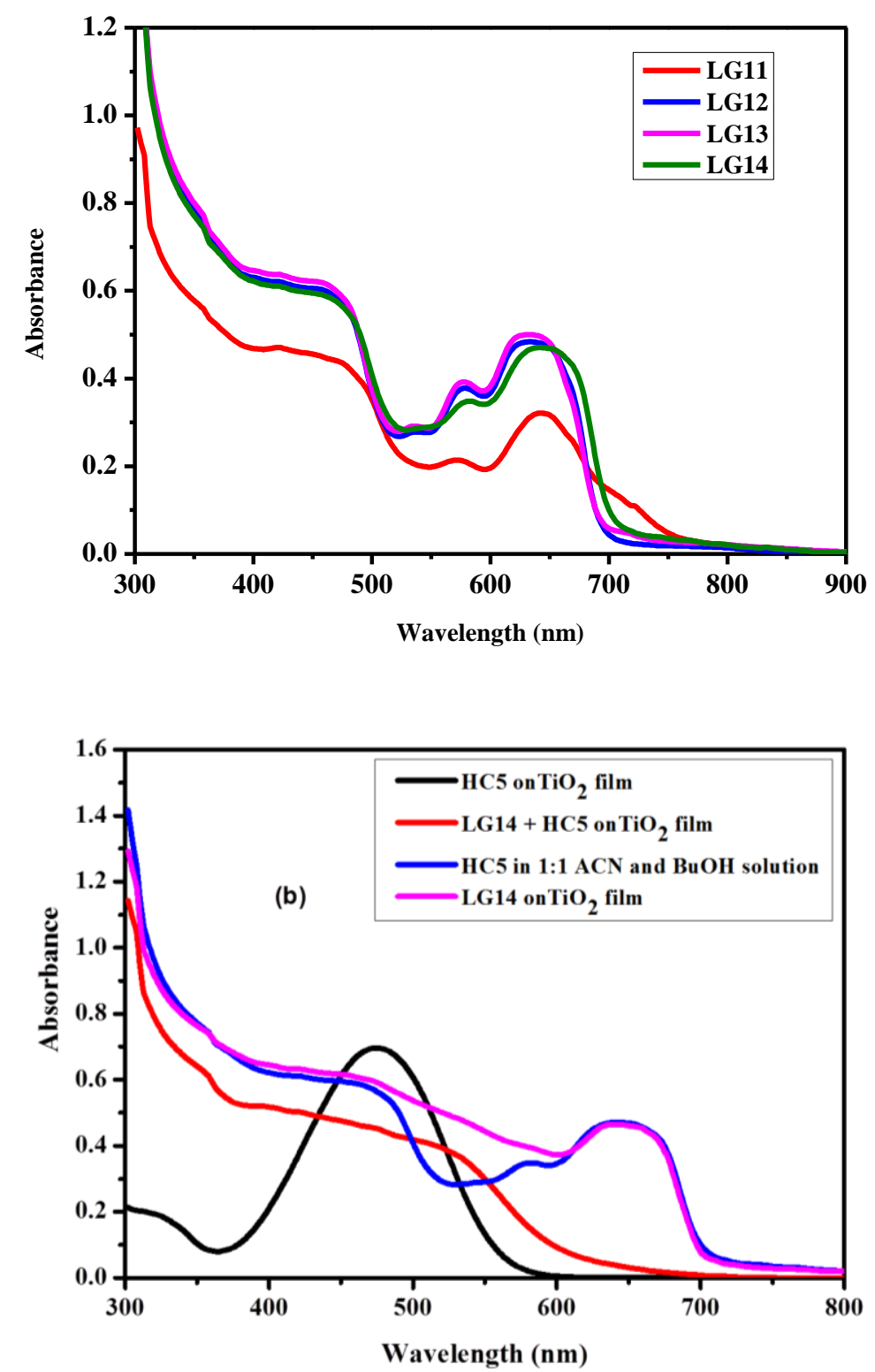

Figure 2: (a) Absorption spectra LG11-LG14 porphyrin sensitizers on $\mathrm{TiO}_{2}$, (b) Absorption spectra of HC5, LG14 + HC5 on $\mathrm{TiO}_{2}$ and HC5 in 1:1 ACN and BuOH solution.

coupling between carboxylic acid group and porphyrin ring was more effective. ${ }^{22,42}$ The emission spectra were found to be quenched when adsorbed onto a $6 \mu \mathrm{m}$ thick $\mathrm{TiO}_{2}$ layer, as a consequence of electron injection from singlet state of porphyrin into the conduction band of $\mathrm{TiO}_{2}$ in all four new sensitizers. The singlet state excited lifetimes of all four D- $\pi$-A porphyrin sensitizers were measured in THF solvent and found to be 0.93, 0.76, 0.86 and 0.73 ns of LG11, LG12, LG13 \& LG14, respectively. The singlet excited lifetime was quenched in all four cases only when adsorbed on $\mathrm{TiO}_{2}$. The singlet state energies $\left(\mathrm{E}_{0-0}\right)$ of all four porphyrin sensitizers, calculated from emission and excited spectra, are found to be in 
the range of $\sim 1.85 \pm 0.05 \mathrm{eV}$, which are less than the value of the reference compound, ZnTPP.

Table 1: Photophysical properties of porphyrin sensitizers LG11-LG14

\begin{tabular}{|c|c|c|c|c|c|c|c|}
\hline Dyes & $\begin{array}{l}\text { Absorption } \lambda_{\max } \mathbf{n m} \\
\left(\log \varepsilon, M^{-1} \mathbf{c m}^{-1}\right)^{a}\end{array}$ & $\begin{array}{c}\text { Emission } \\
\lambda_{\max } \mathbf{n m}^{\mathbf{b}},(\Phi)^{\mathbf{c}}\end{array}$ & $\begin{array}{ll}\tau,,^{\mathrm{d}} & \mathbf{n s} \\
(\mathrm{A} \%) & \end{array}$ & $\begin{array}{l}E_{0-0} \\
(\mathrm{eV})^{\mathrm{e}}\end{array}$ & $\begin{array}{l}E_{1 / 2}(\mathbf{V}) \\
\operatorname{SCE}^{\mathrm{f}}\end{array}$ & vs. & $E_{\text {oxd }}{ }^{*}(V)$ \\
\hline \multirow[t]{3}{*}{ LG11 } & $458(6.08)$ & $671(0.17)$ & $0.93(63)$ & 1.87 & 0.85 & & -1.02 \\
\hline & $575(4.31)$ & & $2.10(37)$ & & & & \\
\hline & $674(4.63)$ & & & & & & \\
\hline \multirow[t]{3}{*}{ LG12 } & $457(6.20)$ & $670(0.20)$ & $0.76(53)$ & 1.88 & 0.85 & & -1.03 \\
\hline & $584(4.17)$ & & $1.84(47)$ & & & & \\
\hline & $662(4.90)$ & & & & & & \\
\hline \multirow[t]{3}{*}{ LG13 } & $458(5.56)$ & $671(0.19)$ & $0.86(71)$ & 1.88 & 0.86 & & -1.02 \\
\hline & $584(3.98)$ & & $1.80(29)$ & & & & \\
\hline & $663(4.69)$ & & & & & & \\
\hline \multirow[t]{3}{*}{ LG14 } & $460(5.11)$ & $678(0.18)$ & $0.73(46)$ & 1.80 & 0.85 & & -1.02 \\
\hline & $581(3.81)$ & & $3.00(64)$ & & & & \\
\hline & $667(4.30)$ & & & & & & \\
\hline
\end{tabular}

${ }^{a}$ Absorption spectra were measured in THF solution at room temperature. ${ }^{b}$ Emission spectra were measured in THF solution at room temperature. 'Quantum yields of sensitizers is measured with the reference compound 5,10,15,20-tetra- phenyl zinc porphyrin (ZnTPP). ${ }^{\mathrm{d}}$ Singlet excited-state lifetimes were measured in THF solution. ${ }^{\mathrm{e}} \mathrm{E}_{0-0}$ was determined from the intersection of normalized absorption

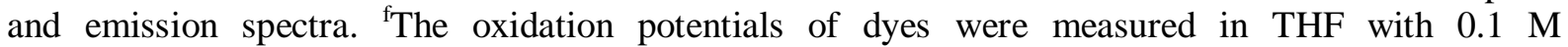
tetrabutylammonium hexafluorophosphate $\left(\mathrm{TBAPF}_{6}\right)$ with a scan rate of $50 \mathrm{mVs}^{-1}(\mathrm{vs} \mathrm{SCE})$.

\subsection{Electrochemical and Spectroelectrochemical Studies}

Cyclic voltammetry studies were performed to evaluate the HOMO - LUMO levels of LG11-LG14 porphyrin dyes using $0.1 \mathrm{M}$ solution of TBAP in THF with the internal 
reference of $\mathrm{Fc} / \mathrm{Fc}^{+}$couple. Each porphyrin sensitizer undergoes two reversible oxidations and a quasi-reversible reduction. First ground state oxidation potentials (Eox) of LG11-LG14 are found to be $0.85,0.85,0.86$ and $0.85 \mathrm{~V}$ (Figure 3, Table 1), respectively, versus the standard calomel electrode (SCE).The reduction potentials of these porphyrin sensitizers were found to be around $-1.40 \mathrm{~V}$ (See supporting information). The excited state oxidation potential ( $E^{*}$ Ox) of each porphyrin sensitizer, calculated using an expression, $E^{*}$ OX $=E_{0 x}-E_{0-0}$, lies in the range of $-1.02 \mathrm{~V}$ (Table 1$)$, which is considerably more negative than the conduction band $(\mathrm{CB})$ edge of $\mathrm{TiO}_{2}(-0.5 \mathrm{~V}) .{ }^{43}$ Figure 4 represents an energy level diagram of LG11-LG14 dyes, indicating that active dye regeneration and electron injection processes for all dyes on $\mathrm{TiO}_{2}$ dye-sensitized systems are energetically favourable. From the results, it is clear that the introduction of a planar group into LG11 indicates the lowest electrochemical energy gap among all the dyes, which agrees with its broad range absorption spectrum.

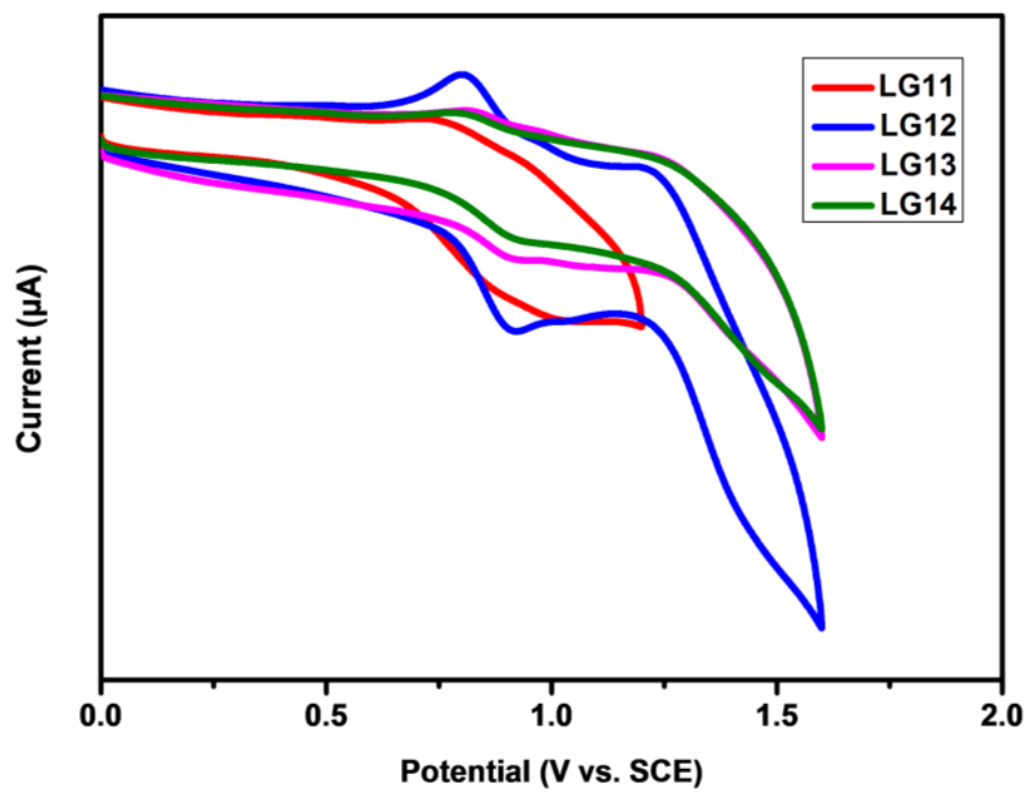

Figure 3: Cyclic voltammograms of LG11-LG14 porphyrins in THF using 0.1 M TBAP. 


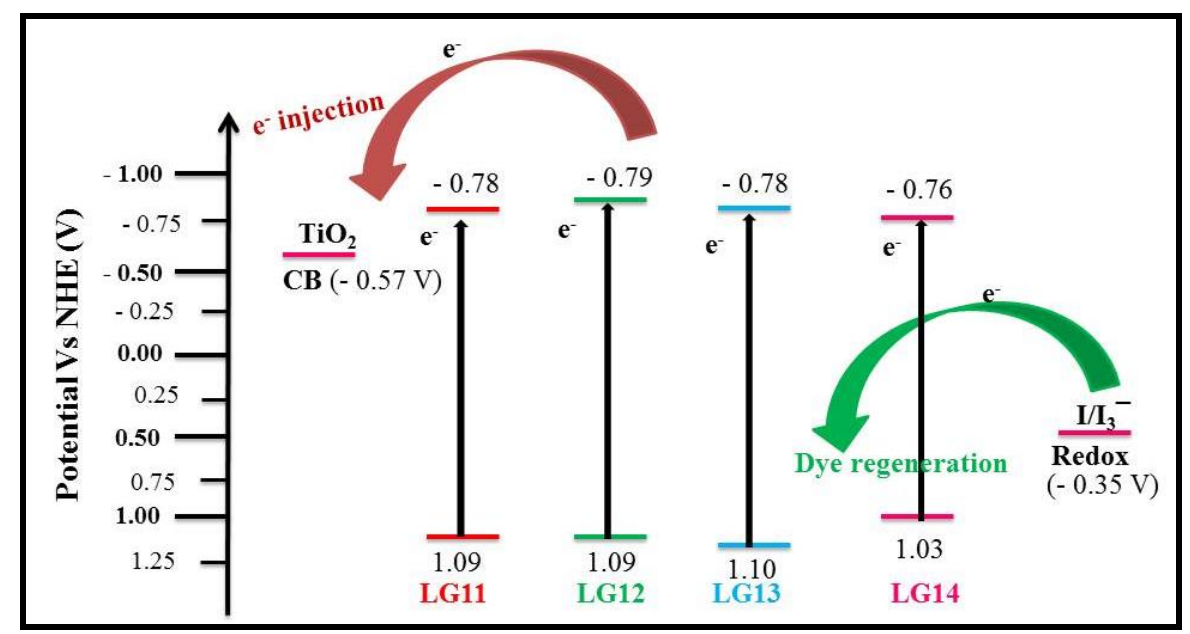

Figure 4: An energy-level diagram of LG11-LG14 porphyrins, electrolyte and $\mathrm{TiO}_{2} ; \mathrm{E}(\mathrm{HOMO})=$ $\mathrm{E}_{\mathrm{ox}}$ and $\mathrm{E}_{(\mathrm{LUMO})}=\mathrm{E}_{(\mathrm{HOMO})}-\mathrm{E}_{0-0}$.

In order to gain insight into the electronic properties of the oxidized species of the sensitizer, spectroelectrochemical studies were performed under the controlled oxidation potential. $^{44}$ Figure 5 shows spectral changes of LG14 sensitizer at an applied oxidation potential of $+0.90 \mathrm{~V}$. During this process, the Q-band at $666 \mathrm{~nm}$ sees decreasing its intensity with a significant hypsochromic shift of $20 \mathrm{~nm}$, and formation of a new band at $565 \mathrm{~nm}$. Similar trend of decreasing intensity and bathochromic shift are also observed in Soret band $(458 \mathrm{~nm})$, and the formation of a new band at $433 \mathrm{~nm}$ accompanied with increasing in its intensity. The isosbestic points observed at 442, 483, and $608 \mathrm{~nm}$, which clearly indicate the oxidation of porphyrin sensitizer, which clearly indicates that the oxidation gives a single product. The porphyrin cation radical generated at $+0.90 \mathrm{~V}$ cannot be fully recovered to its neutral form when the applied potential changed to $+0.2 \mathrm{~V}$. These results are supporting the quasireversible property of cyclic voltammogram of porphyrin sensitizer (LG14). The porphyrin radical which is formed after the completion of spectroelectrochemical analysis exhibits characteristics of porphyrins. This is due to chemical changes that occurred in the substituent groups. From the results, it is anticipated that the LG14 sensitizer is exhibiting greater oxidative stability during spectroelectrochemical studies, similar to our previously reported sensitizers. ${ }^{22}$ Similar types of spectral changes are also observed in other porphyrin sensitizers (Figure S28). 


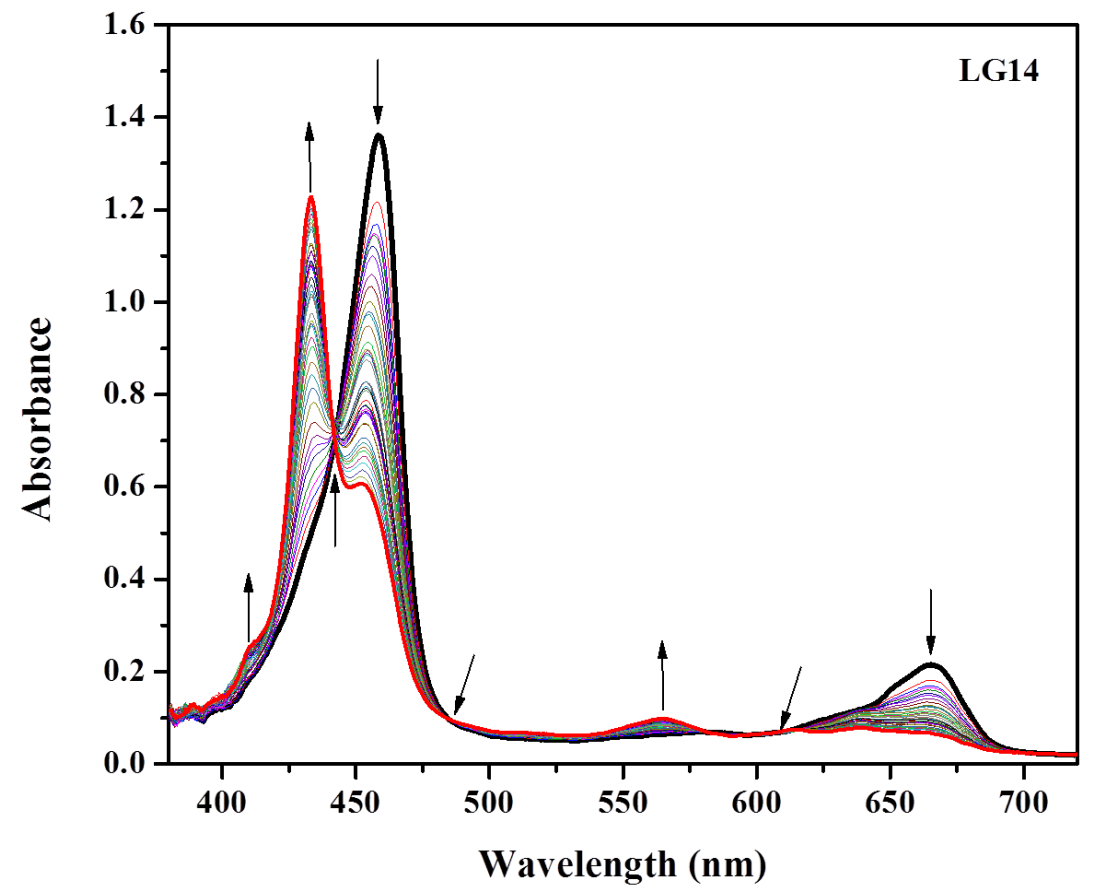

Figure 5: Oxidative OTTLE studies of LG14 in 0.3 M TBAP/THF with an applied potential of +0.90 $\mathrm{V}$ (vs SCE/KCl).

\subsection{Theoretical Studies}

To provide an insight into the structural, electronic, and optical properties of the LG11-LG14 dyes, density functional theory (DFT) and time-dependent density functional theory (TDDFT) calculations were performed with a basic functional set of the B3LYP/631G(d,p) level. Figure S25 shows the ground state optimized structures of LG11-LG14 encompass donor and acceptor moieties separating porphyrin ring with ethynyl $\pi$-spacer. From this optimized structures, one can deduce that the sensitizer LG11 is in planar structure and tends to form aggregation in solution as well as on $\mathrm{TiO}_{2}$ surface that affects the efficiency of the device. The bulky substituents phenyl (LG12) and 4-hexyl phenyl (LG13 \& LG14) of donor imidazole group are not in plane and by consequence minimizes the aggregation. The anchoring groups of all the dyes are positioned in a plane with the porphyrin macrocycle, except LG14, due to insertion of thiophene moiety. Figure 6 shows frontier molecular orbitals (FMOs) of LG11-LG14 dyes. In all sensitizers, the electron density distribution of HOMO and LUMO is occupied partially on donor, porphyrin and acceptor moieties and in HOMO-1, LUMO+1. The electron density is mainly on porphyrin macrocycle. In contrast, in HOMO-2, it is distributed mainly on donor moiety and slightly on the porphyrin ring, and in LUMO+2, it is located mainly on the acceptor group. Therefore, the electron transfer processes from donor to acceptor group through the porphyrin macrocycle and eventually 
electron injection into the conduction band of $\mathrm{TiO}_{2}$ is theoretically feasible. The HOMO-LUMO gaps of these sensitizer systems are in the order of LG11 > LG12 $\approx$ LG13 > LG14. Moreover, using B3LYP/6-31G(d,p), the TD-DFT studies of these dyes were calculated for the better understanding of the excited-state transitions with the framework of the polarizable continuum model (PCM) in tetrahydrofuran (THF) solvent with M06-2X function. The obtained results are in good agreement with the experimental values. The calculated vertical excitation energies for singlet together with calculated oscillator strengths are listed in Table S2.

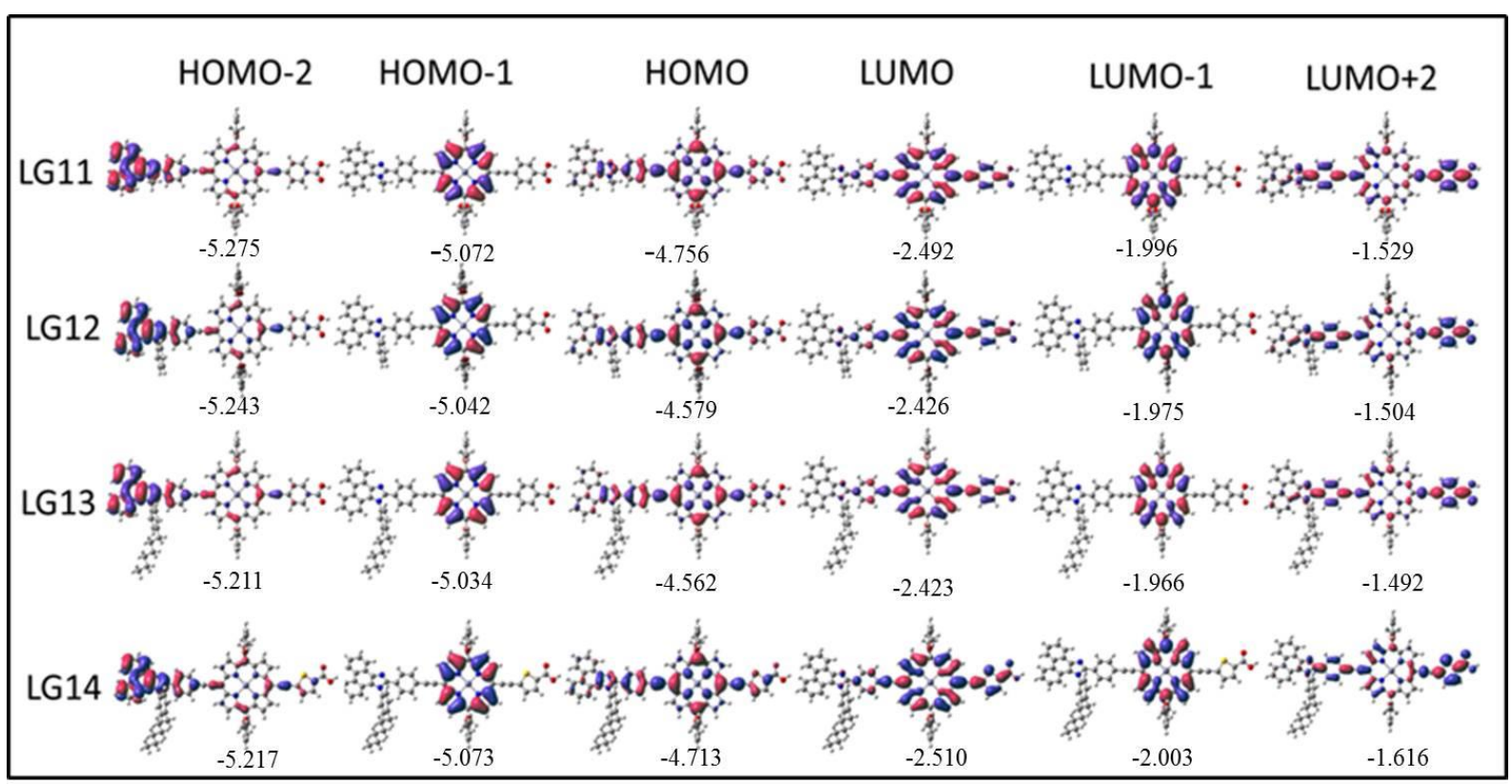

Figure 6: Isodensity (0.02) plots of FMOs and the energy values in eV by using the B3LYP method 6-31G(d,p).

\subsection{Device Studies}

The photovoltaic studies of the devices fabricated using LG11-LG14 porphyrin sensitizers and co-sensitized system (LG14/HC5) were evaluated using standard mesoporous $8 \mu \mathrm{m}$ thick $\mathrm{TiO}_{2}$ films and an acetonitrile based redox electrolyte (composed of 0.6 M 1,2-dimethyl-3propylimidazolium iodide (DMPII), 0.05 $\mathrm{M} \mathrm{I}_{2}, 0.1 \mathrm{M} \mathrm{LiI}$, and 0 - $0.5 \mathrm{M}$ 4-tert-buylpyridine (TBP) Figure. S26 \& S27). The detailed fabrication method was described in our earlier studies. $22,37,38$ The photocurrent action spectra of all dyes exhibit a broad spectral response with two maxima at $480 \mathrm{~nm}$ and $680 \mathrm{~nm}$ and are exemplified in Figure 7a, indicating the Soret and Q band absorbances. At the wavelength of $480 \mathrm{~nm}, \mathbf{L G 1 4}$ sensitizer showed IPCE of $80 \%$, whereas at $680 \mathrm{~nm}$,IPCE was above $80 \%$ (See Table 2). On the other hand, we have 
observed only 60\% IPCE in case of LG11 sensitizer, which might be due to the charge recombination. This is clearly revealing the effect of the planar donor in LG11 sensitizer, where phenanthroimidazole moiety was $\mathrm{N}$-substituted by simple methyl group compared to other LG12-LG14 sensitizers having N-substitution with phenyl and 4-hexyl phenyl groups, respectively. The onset of all sensitizers was at $800 \mathrm{~nm}$. In LG14, the intensity of IPCE spectrum is little higher and onset extends up to $820 \mathrm{~nm}$ due to the presence of heterocyclic thiophene moiety. ${ }^{37,38}$ Thus, the onset wavelength thresholds (Figure 7a) lie in the order of LG11 < LG12 $\approx$ LG13 < LG14, which are consistent with the sequence of photocurrent $J_{S C}$.
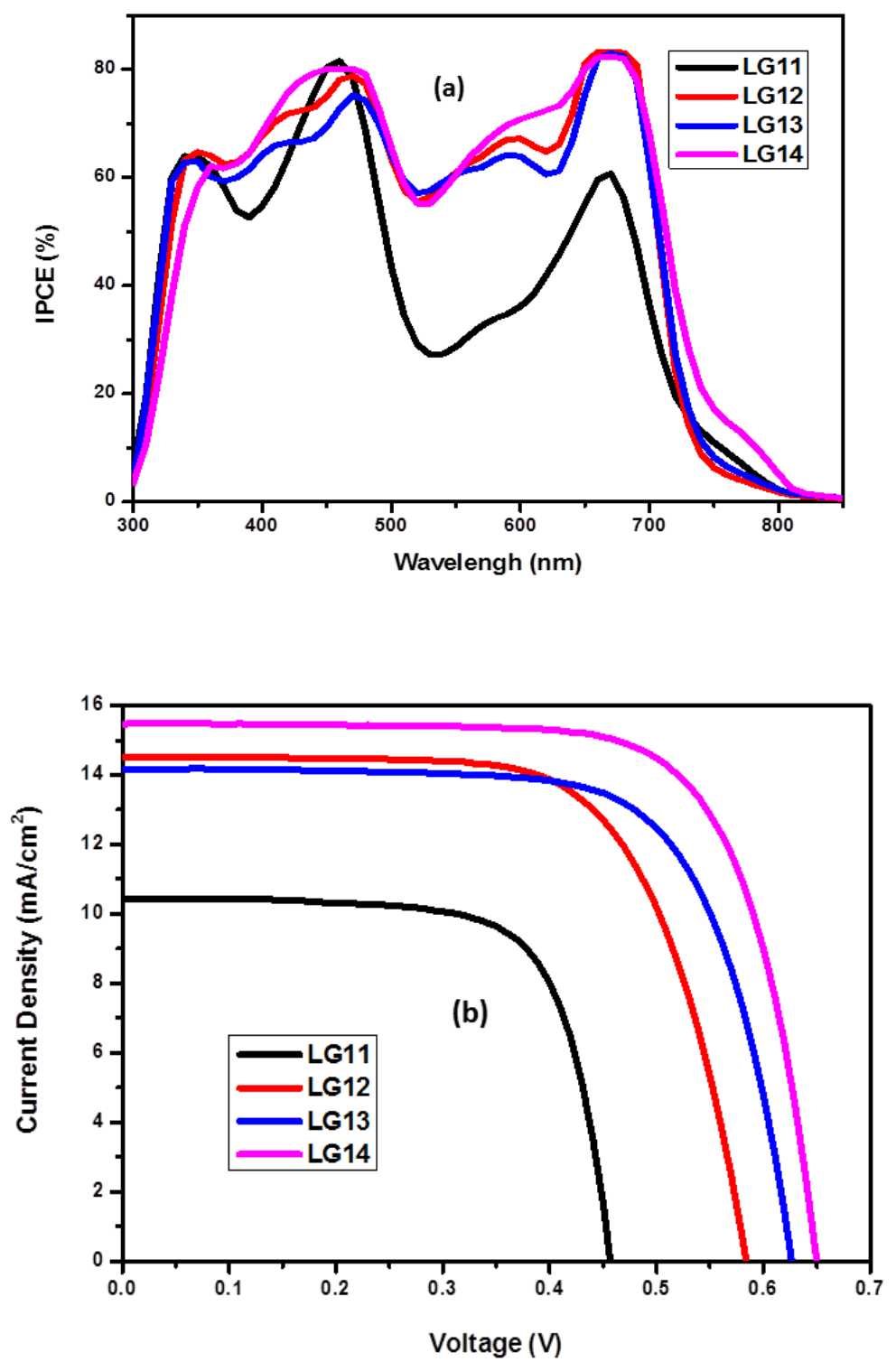

Figure 7: (a) Photocurrent action spectra and (b) Current-voltage characteristics of LG11-LG14 sensitizers. TBAP concentration $0 \mathrm{M}$. 
Table 2: Phtovoltaic Performance Parameters of LG11-LG14 Porphyrin Sensitizers

\begin{tabular}{|c|c|c|c|c|c|c|}
\hline Dye & TBP (mM) & $\begin{array}{l}\text { IPCE } \\
(\%)^{\text {a,b }}\end{array}$ & $\begin{array}{c}\mathrm{J}_{\mathrm{SC}} \\
\left(\mathrm{mA} / \mathrm{cm}^{2}\right)^{\mathrm{a}}\end{array}$ & $\begin{array}{l}\mathbf{V}_{\text {OC }} \\
(\mathrm{V})\end{array}$ & $\mathbf{F F}^{\mathrm{a}}$ & $\eta(\%)$ \\
\hline \multirow[t]{4}{*}{ LG11 } & $0.0 \mathrm{mM}$ & 81 & 10.45 & 462 & 0.71 & 3.38 \\
\hline & $0.1 \mathrm{mM}$ & 70 & 07.11 & 480 & 0.72 & 2.48 \\
\hline & $0.3 \mathrm{mM}$ & 61 & 06.05 & 501 & 0.72 & 2.20 \\
\hline & $0.5 \mathrm{mM}$ & 49 & 04.65 & 535 & 0.71 & 1.73 \\
\hline \multirow[t]{4}{*}{ LG12 } & $0.0 \mathrm{mM}$ & 80 & 14.52 & 584 & 0.67 & 5.73 \\
\hline & $0.1 \mathrm{mM}$ & 77 & 12.19 & 603 & 0.69 & 5.10 \\
\hline & $0.3 \mathrm{mM}$ & 66 & 10.16 & 631 & 0.66 & 4.21 \\
\hline & $0.5 \mathrm{mM}$ & 49 & 06.57 & 665 & 0.72 & 3.16 \\
\hline \multirow[t]{4}{*}{ LG13 } & $0.0 \mathrm{mM}$ & 76 & 14.17 & 632 & 0.70 & 6.25 \\
\hline & $0.1 \mathrm{mM}$ & 70 & 11.38 & 653 & 0.69 & 5.13 \\
\hline & $0.3 \mathrm{mM}$ & 61 & 09.36 & 684 & 0.72 & 4.56 \\
\hline & $0.5 \mathrm{mM}$ & 58 & 08.23 & 691 & 0.72 & 4.10 \\
\hline \multirow[t]{4}{*}{ LG14 } & $0.0 \mathrm{mM}$ & 80 & 15.81 & 651 & 0.72 & 7.45 \\
\hline & $0.1 \mathrm{mM}$ & 75 & 13.12 & 663 & 0.73 & 6.34 \\
\hline & $0.3 \mathrm{mM}$ & 69 & 11.69 & 685 & 0.72 & 5.69 \\
\hline & $0.5 \mathrm{mM}$ & 56 & 09.04 & 692 & 0.72 & 4.50 \\
\hline
\end{tabular}

${ }^{\mathrm{a}}$ Error limits: $J_{S C} \pm 0.20 \mathrm{~mA} / \mathrm{cm}^{2}, V_{O C}= \pm 0.30 \mathrm{mV}, \mathrm{FF}= \pm 0.03 .{ }^{\mathrm{b}}$ Wavelength, $600 \mathrm{~nm}$

Figure $7 \mathrm{~b}$ shows the current density-voltage $(J-V)$ curves of the DSSCs based on the LG11-LG14 dyes measured at simulated AM $1.5 \mathrm{G}$ irradiation $\left(100 \mathrm{~mW} \mathrm{~cm} \mathrm{~cm}^{-2}\right)$, and their photovoltaic parameters are summarized in Table 2. The power conversion efficiencies (PCE) for LG11-LG14 dyes lie in the range of 3.38-7.45\%. The low efficiency of LG11 observed is may be due to the more dye aggregation caused by the methyl phenanthroimidazole donor and extended $\pi$-conjugated scaffold. ${ }^{45}$ Tethering of non-planar $\mathrm{N}$-substituted phenyl and hexyl phenyl phenanthroimidazole donor moieties at the meso- position of porphyrin is an effective approach for improving the $V_{O C}$ and $J_{S C}$ values, thus, enhancing the device efficiency. Phenyl group substitution in LG12 is favourable to induce the enhanced $\varepsilon$. These results show improved $J_{S C}$ value of $14.52 \mathrm{~mA} \mathrm{~cm}{ }^{-2}$ compared to methyl group substituted LG11 $\left(J_{S C}=10.45 \mathrm{~mA} \mathrm{~cm}^{-2}\right)$. Moreover, increased $V_{O C}$ value is also observed in LG12 (581 $\mathrm{mV}$ ) in comparison to $\mathbf{L G 1 1 ~ ( 4 6 3 ~ m V ) ~ w h i c h ~ i s ~ d u e ~ t o ~ h i n d e r i n g ~ t h e ~ c h a r g e ~ r e c o m b i n a t i o n ~ i n ~}$ LG12, thus, increasing the device efficiency from $3.38 \%$ (LG11) to $5.73 \%$ (LG12). The 
hexyl phenyl groups in LG13 and LG14 are further favourable to suppress the dyeaggregation and improve $V_{O C}$ values of 632 and $653 \mathrm{mV}$, respectively. Improvements go also to the $J_{S C}$ value of $15.81 \mathrm{~mA} \mathrm{~cm}^{-2}$ observed in LG14 compared to $\mathbf{L G 1 3}\left(\mathrm{J}_{S C}=14.17 \mathrm{~mA} \mathrm{~cm}-\right.$ ${ }^{2}$ ). This could be attributed to the introduction of the thiophene motif as $\pi$-conjugation between ethylene porphyrin and carboxylic anchoring group. Thus, the devices based on LG13 \& LG14 showed significantly improved efficiencies (6.25 \& 7.45\%, respectively) compared with those of LG11 and LG12 (3.38\% and 5.73\%). These results indicate well that efficient porphyrin sensitizers can be designed by combining highly effective non-planar donors with as $\pi$ - conjugation and heterocyclic aromatic ring having anchoring carboxylic acid group.

\subsection{Kinetic Studies}

The photovoltaic performance of DSSCs was investigated by increasing the concentration of 4-tert-butylpyridine (TBP) in liquid-type electrolyte. Figure S26 illustrates IPCE spectra characteristic of LG11-LG14 sensitizers with TBP concentration of 0.1, 0.3, and $0.5 \mathrm{M}$ and compared with those observed without TBP in liquid electrolyte (Figure 7a). The IPCE data of all sensitizers are given in Table 2, which indicate a destructive effect of the TBP on the IPCE (see Figure S26). With the increasing of TBP concentration, the $V_{O C}$ values are highly improved in all sensitizers (See Table 2, Figure S27). With the electrolyte of 0.5 M TBP, the $V_{O C}$ of LG14 increased to $690 \mathrm{mV}$, compared to the cell without TBP in electrolyte (650 $\mathrm{mV})$. The improvement in $V_{O C}$ agrees in with our previous report of porphyrin sensitizers. ${ }^{22}$

To further understand the molecular structure dependent $V_{\mathrm{OC}}$ for LG11-LG14 sensitizers, we first measured the relative conduction band position of $\mathrm{TiO}_{2}$ by means of a charge extraction method. Figure 8 shows $V_{O C}$ as a function of electron density for all dyes. A linear increase in $V_{O C}$ as a function of electron density was observed for all DSSCs. Notably, the plots for all dyes overlapped with each other, indicating that all of the dyes have almost the same effect on the conduction band of $\mathrm{TiO}_{2}$ regardless of the various $\pi$-spacers between porphyrin macrocycle and anchoring carboxylic acid. Therefore, the molecular structure dependent $V_{O C}$ for all DSSCs should be attributed to the extent of charge recombination that is related to the electron lifetime $(\tau)$ in $\mathrm{TiO}_{2}$. Intensity-modulated photovoltage spectroscopy was used to measure $\tau$. 


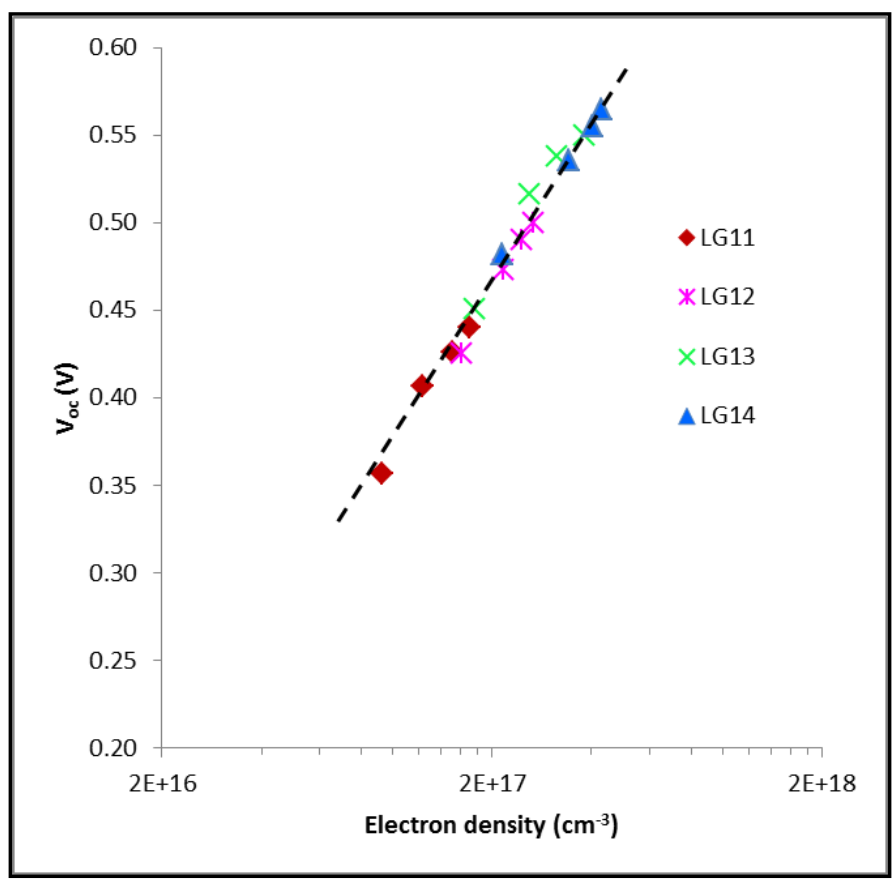

Figure 8: $V_{\mathrm{OC}}$ as a function of electron density for DSSCs sensitized with LG11-LG14. Electron density was measured by means of a charge extraction method.

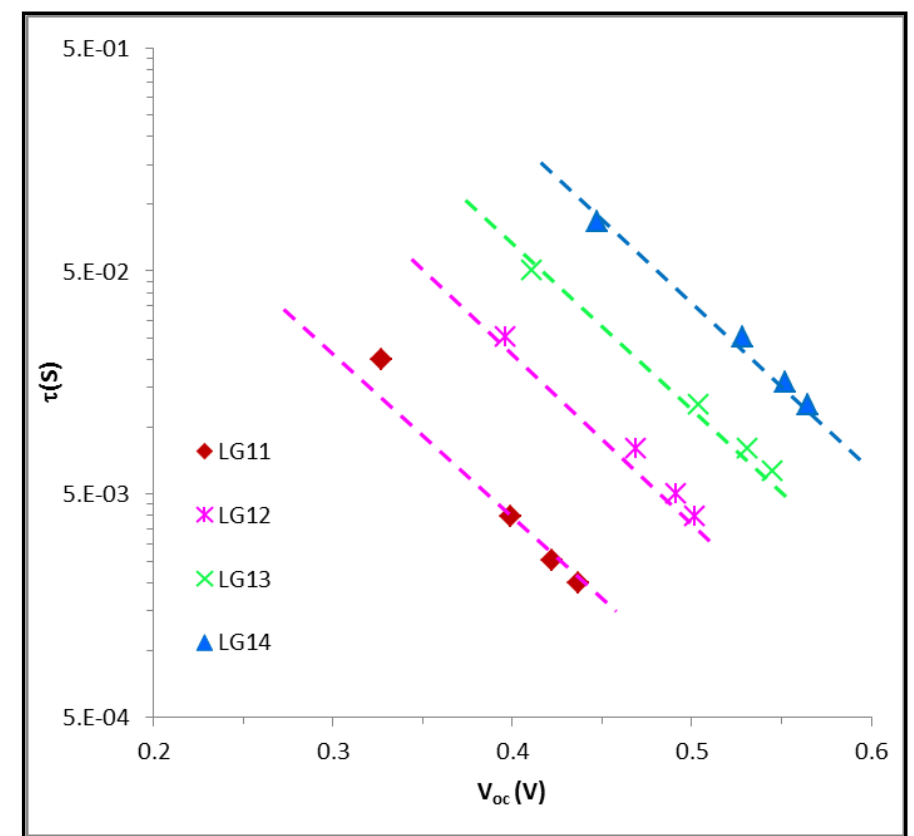

Figure 9: Electron lifetime $(\tau)$ as a function of $V_{\mathrm{OC}}$ for DSSCs sensitized with LG11-LG14. Electron lifetime was measured by means of intensity-modulated photovoltage spectroscopy. 
Figure 9 shows the electron lifetime $(\tau)$ as a function of $V_{O C}$. At a certain electron density, $\tau$ follows the following order: LG14 > LG13 > LG12 > LG11. It can be clearly seen from the Figure 9, the sensitizers LG13 and LG14, having hexylphenyl substitution that further reduces aggregation, when compared to LG11 and LG12 having no substitution or methyl substitution, respectively. Both LG13 and LG14 tend to form uniform dye layers on $\mathrm{TiO}_{2}$ surface, which, by in turn, reduces the concentration of $\mathrm{I}_{3}^{-}$ions in the vicinity of the $\mathrm{TiO}_{2}$ surface. This later explains the electrons longer lifetime and suppression of the charge recombination reactions at the electrolyte $\left(\mathrm{I}_{3}\right.$-ions $) / \mathrm{TiO}_{2}$ interface. As a result, enhnaced efficiency was observed in LG13 and LG14 sensitizers, when compared to LG11 and LG12 sensitizers.

We adopted nanosecond laser flash photolysis spectroscopy to investigate and relate the transient kinetics of dye regeneration by electrolyte of LG11-LG14 dyes to their respective photovoltaic performances, energy levels, etc. studied above. Nanosecond laser flash photolysis has become an ideal tool for investigating DSSC interfacial kinetics, considered to be one of the crucial steps for the DSSC performance. ${ }^{46-48}$ To be noted here, we used high laser intensity enough to record suitable transient absorbance signals. This should not cause any significant change in the decay rate as has been also observed by the Grätzel group. ${ }^{49}$ The transient optical signals (or transient absorption signals $\Delta \mathrm{OD}$ ) in Figure 10, represent the concentration of oxidized dye sensitizer (positive $\Delta \mathrm{OD}$ ) instead of that of the bleached ground state of the dye sensitizer for which we measured very poor signals, (both have the same decay lifetime), following electron injection from the dye to the conduction band of $\mathrm{TiO}_{2}$. As for the fitting of the transient decay graphs, a good approach was developed and adopted for a quantitative comparison of the data for the different dyes, with and without electrolytes. ${ }^{50}$ We use, instead, the weighted average of logarithmic lifetimes from a biexponential fit to the data

$$
\log <\tau>=\Sigma \operatorname{Ailog}(\tau \mathrm{i})
$$

where, $A_{\mathrm{i}}$ is the fractional amplitude for each component related to relaxation excited state relaxation, recombination or dye regeneration. The absorption decays in presence of electrolyte (Figure 10), in acetonitrile, show half-times $\left(\tau_{1 / 2}\right)$ of $4.10,4.19,5.25$ and $4.75 \mu \mathrm{s}$, 


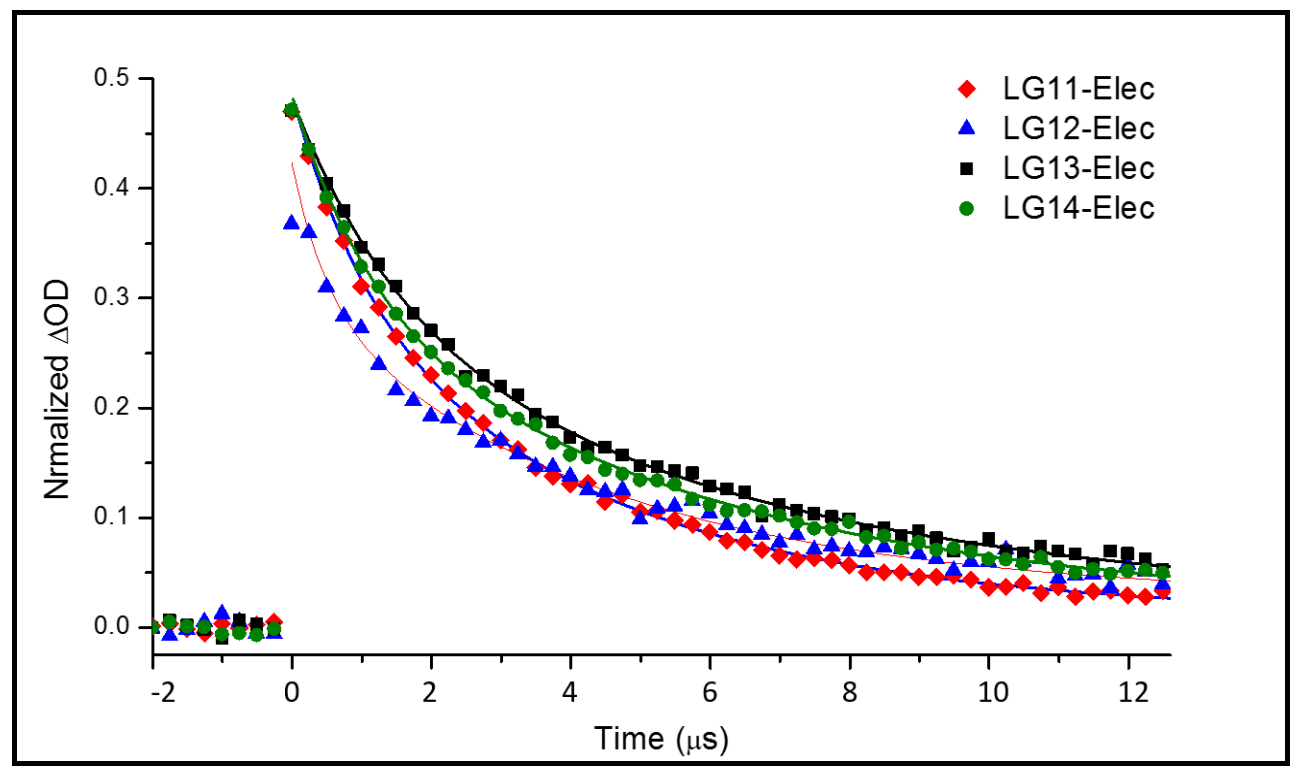

Figure 10: Transient absorbance decay profiles obtained upon nanosecond pulsed laser excitations (band with $6 \mathrm{~ns}$ ) on mesoporous $\mathrm{TiO}_{2}(7 \mu \mathrm{m})$ films sensitized with of LG11-LG14 dyes at a laser excitation of $474 \mathrm{~nm}$ and monitored at $500-550 \mathrm{~nm}$ for for oxidative dye, in the presence of the LiI// $\mathrm{I}_{2}$ electrolyte (Dyesol high performance electrolyte, ELHP; No TBP added).

implying the dye regeneration dynamics by electrolyte redox system of the above LG11LG14 porphyrin dyes. These measured decays lifetimes are within the order of rates mentioned by Booschloo et al. and thus prove efficient dye regeneration by electrolyte redox system of the above porphyrin dyes. ${ }^{51} \mathrm{~A}$ fast dye regeneration implies a high current density collected at the anode. Here, the three dyes (LG12-LG14) produce similar current density collected (within bar errors), in Table 2, and because they produce almost similar photocurrent action spectra overlap (Figure 7), they do present almost similar dye regeneration time decays, $\tau_{1 / 2}$, (within bar errors). Exception done for LG11 for which regeneration time decay is also same as the rest of dyes but shows very lower current density produced. This can be explained by the lower IPCE over the whole visible spectrum compared to LG12-LG14 (Figure 7).

In addition, based on energy-level diagram of LG11-LG14 porphyrins in Figure 4, all respective dyes present diving forces higher than $0.25 \mathrm{~V}$ of that of redox potential of $\mathrm{I}^{-} / \mathrm{I}_{3}{ }^{-}$ which is -0.35 V vs NHE. Daeneke et al. have established that Quantitative dye regeneration (theoretical regeneration yield 99.9\%) can be achieved with a driving force of 20-25 kJ mol-1 $(\Delta \mathrm{E} \approx 0.20-0.25 \mathrm{~V}) .{ }^{52}$ Thus, much higher driving force (more than $0.25 \mathrm{~V}$ vs Vacuum) would not necessary make a difference since after $0.25 \mathrm{~V}$ the dye regeneration 
process is diffusion controlled. Thus, in light of this later, dye regeneration times recorded in presence of electrolyte do corroborate with the driving forces, and with measured respective $J_{\mathrm{sc}}$.

\subsection{Co-sensitization Studies}
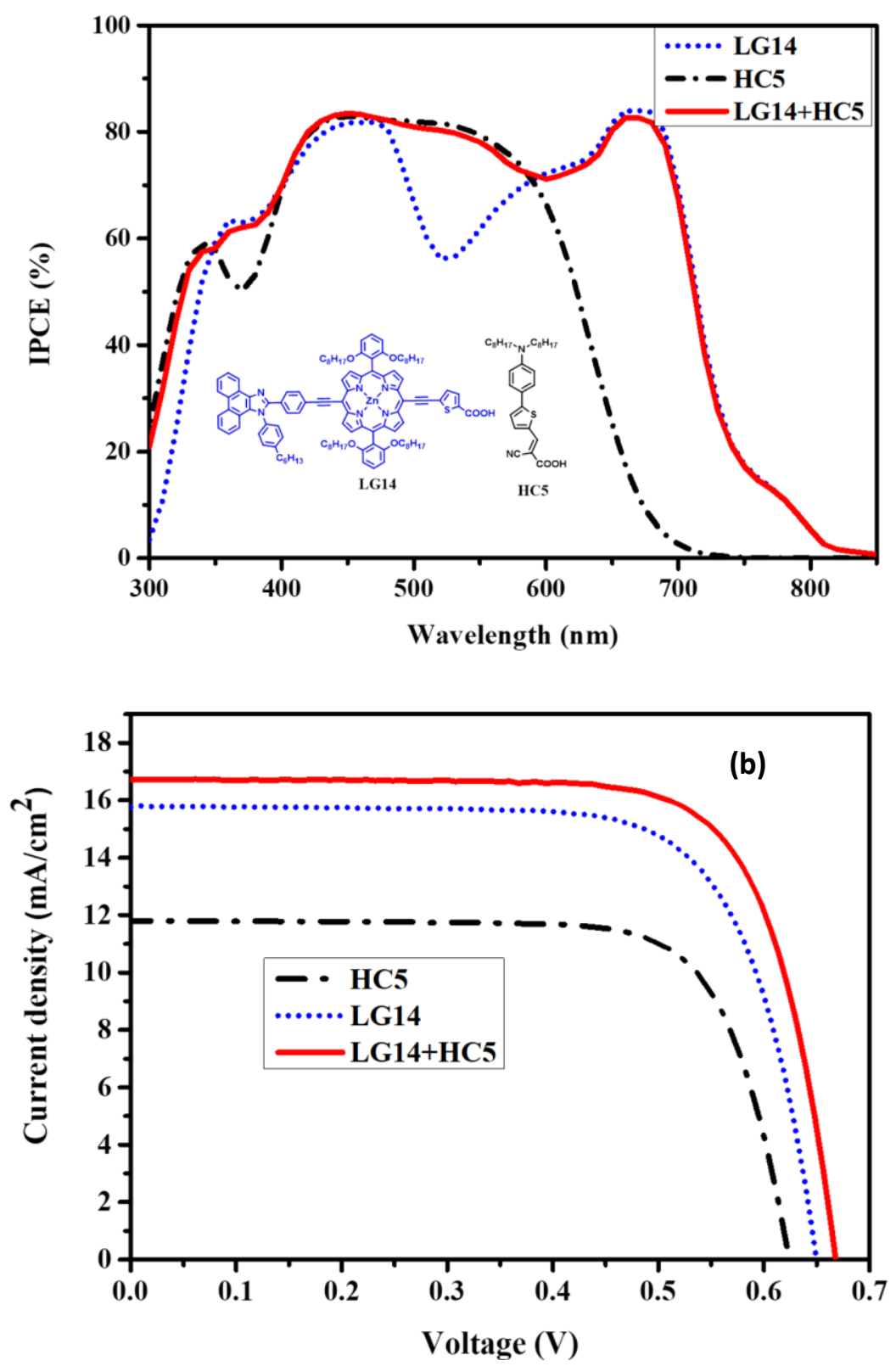

Figure 11: (a) Photocurrent action spectra and (b) J-V characteristics of LG14, HC5, and LG14/HC5 devices. 
Table 3: Photovoltaic Performance Parameters of LG14, HC5, and LG14+HC5 Devices

\begin{tabular}{ccccccc}
\hline Dyes & $\begin{array}{c}\text { Jsc } \\
\left(\mathbf{m A ~} \mathbf{~ c m}^{-2}\right)^{\mathbf{a}}\end{array}$ & $\begin{array}{c}\text { Voc } \\
(\mathbf{m V})^{\mathbf{a}}\end{array}$ & $\mathbf{F F}^{\mathbf{a}}$ & $\eta(\%)$ & $\begin{array}{c}\text { Adsorbed amount } \\
\text { of LG14 }\left(\mathbf{m o l ~ c m}^{-2}\right)\end{array}$ & $\begin{array}{c}\text { Adsorbed amount } \\
\text { of HC5 dye }\left(\mathbf{m o l ~ c m}^{-2}\right)\end{array}$ \\
\hline LG14 & 15.81 & 650 & 0.72 & 7.45 & $1.02 \times 10^{-7}$ & \\
HC5 & 11.79 & 624 & 0.75 & 5.52 & & $7.05 \times 10^{-8}$ \\
LG14+HC5 & 16.72 & 669 & 0.73 & 8.27 & $8.85 \times 10^{7}$ & $6.79 \times 10^{-8}$ \\
\hline
\end{tabular}

${ }^{\mathrm{a}}$ Error limits: $J_{S C} \pm 0.20 \mathrm{~mA} / \mathrm{cm}^{2}, V_{O C}= \pm 0.30 \mathrm{mV}, \mathrm{FF}= \pm 0.03$.

Both in solution (Figure 1) and on $\mathrm{TiO}_{2}$ (Figure 2a), porphyrin has valley in absorption at 500-550 $\mathrm{nm}$ region and this reflect even in IPCE spectra (Figure 7a). In order to further improve the efficiency of the device, one has to enhance absorption in that region of absorption spectra of LG14. For this reason, we have used an organic dye, N,Ndioctylaminophenyl (HS5), whose absorption properties are complimentary to LG15 sensitizer. ${ }^{28}$ Figure 11a exemplified the IPCE spectra of co-sensitized device (LG14/HC5) and the corresponding photovoltaic data are presented in Table 3 . From the Figure 8 , it suggests that the valley present in IPCE spectrum of LG14 sensitizer at around $550 \mathrm{~nm}$ has risen due to the complementary absorption of co-sensitizer HC5 and as a result IPCE has enhanced. The co-sensitized device further suppressed dye-aggregation and hindering of charge recombination between injected electron in $\mathrm{TiO}_{2}$ and redox medium $\left(\mathrm{I}^{-} / \mathrm{I}_{3}{ }^{-}\right)$. This results in increased $J_{S C}, V_{O C}$ and efficiency $(\eta)$ values of $16.72 \mathrm{~mA} \mathrm{~cm}^{-2}, 670 \mathrm{mV}$, and $8.27 \%$ in LG14/HC5 device, which is greater than individual devices of LG14 $\left(J_{S C}=15.81, V_{O C}=\right.$ $650 \mathrm{mV}$, and $\eta=7.45 \%)$ and HC5 $\left(J_{S C}=11.79, V_{O C}=624 \mathrm{mV}\right.$, and $\left.\eta=5.52 \%\right)$. Therefore, $V_{O C}, J_{S C}$, and $\eta$ of this kind of cocktail DSCs could be further increased by selecting suitable co-sensitizer dye having steric hindrance groups on donor moiety and complementary absorption spectra for porphyrin dyes.

\subsection{Thermogravimetric analysis}

Thermogravimetric analysis also carried out for LG11-LG14 porphyrin sensitizers to get information on thermal stability of sensitizers, which are valuable information for overall device durability. In general tetraphenyl porphyrin and its metallo derivatives are thermally stable up to $400{ }^{\circ} \mathrm{C} .{ }^{53}$ Figure 12 shows the thermal behavior of LG14 dye, and it is clear that the sensitizer is stable up to $200{ }^{\circ} \mathrm{C}$. A very low initial weight loss observed between 200 and 
$250{ }^{\circ} \mathrm{C}$, and it is attributed due to the removal of the carboxyl anchoring group from sensitizer. A similar trend in thermal stability was also obtained in other sensitizers of this series (see Figure S28). It is clear from the thermal data that these dyes are highly durable for longstanding outdoor applications.

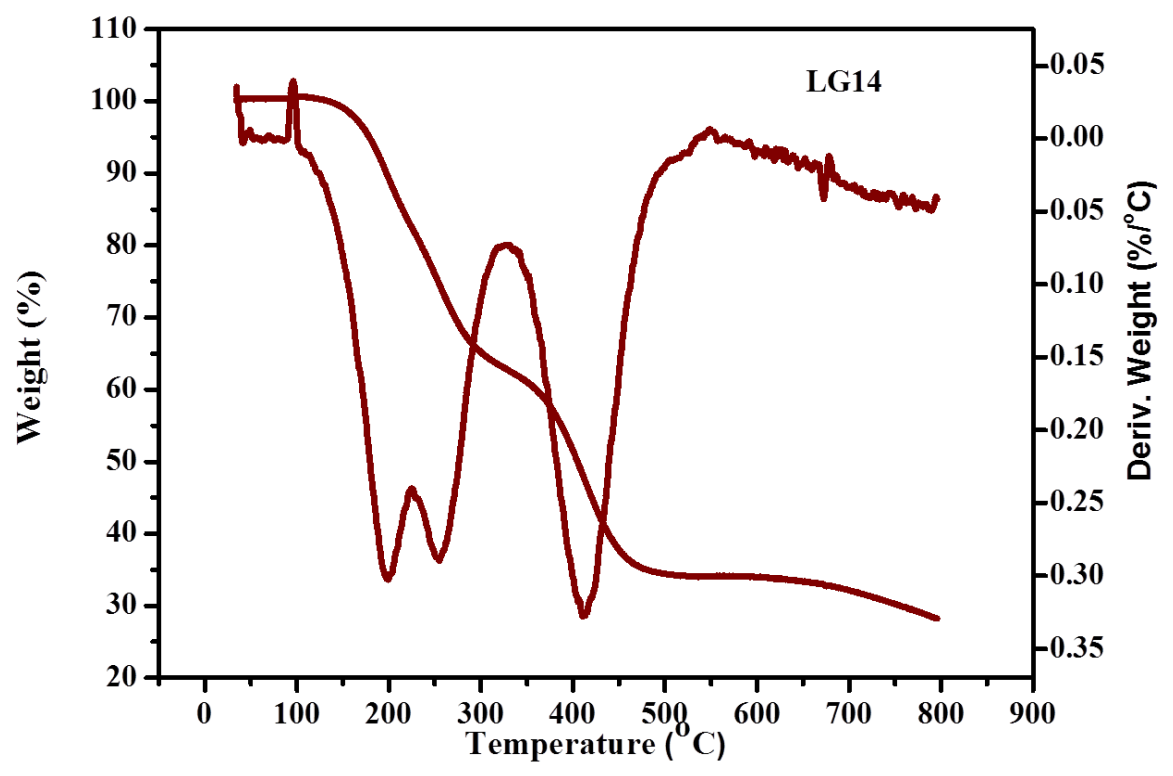

Figure 12: TGA spectra of LG14 sensitizer with a heating rate $10{ }^{\circ} \mathrm{C} \mathrm{min}^{-1}$ under nitrogen gas.

\section{Conclusions}

Porphyrin dyes having phenanthroimidazole bearing various substituents have been systematically investigated as sensitizers for DSSCs. LG12 and LG13 shown improved photovoltaic properties than the LG11, this could be due to the phenyl and hexyl phenyl substitution to the phenanthroimidazole ring. Besides, IPCE spectra for LG12-LG14 dyes observed more than $80 \%$ at the wavelengths of $480 \mathrm{~nm}$ and $680 \mathrm{~nm}$, but lower IPCE spectra in the case of LG11 might be due to the planner geometry which leads to the aggregation during photovoltaic studies. LG13 and LG14 had shown reduced dye aggregation which resulted into the improvement of $\mathrm{V}_{\mathrm{OC}}$ to $460 \mathrm{mV}$ and $650 \mathrm{mV}$. Moreover, in LG14 the ethynylthiophene conjugation shown the red shifts in absorption and enhances electron injection efficiency $\left(\eta_{\text {inj }}\right)$, leading to power conversion efficiency of $7.45 \%\left(J_{S C}=15.81 \mathrm{~mA}\right.$ $\mathrm{cm}^{-2}, V_{O C}=650 \mathrm{mV}$ ) with long-term stability. In addition, the $\mathrm{V}_{\mathrm{OC}}$ values are found to the linear dependence with the increasing TBP concentrations. Furthermore, Lg14 dye was cosensitized with organic dye (HC5) having long alkyl groups and absorption at $\lambda_{\max }$ at $473 \mathrm{~nm}$, this allowed the co-sensitized device for complementary absorption and the same result 
repeated in IPCE spectra. And also co-sensitization further reduced the dye-aggregation and hindering of charge recombination between injected electron on $\mathrm{TiO}_{2}$ and redox medium $\left(\mathrm{I}^{-}\right.$ $/ \mathrm{I}_{3}^{-}$) resulted in enhancement of $J_{S C}, V_{O C}$ and efficiency $(\eta)$ values of $16.72 \mathrm{~mA} \mathrm{~cm}{ }^{-2}, 670 \mathrm{mV}$, and $8.27 \%$ in LG14/HC5 device which is greater than individual devices of LG14 $(\eta=$ 7.45\%) and HC5 $(\eta=5.52 \%)$. Based on the structural, optoelectronic and photovoltaic characterizations, it is anticipated that the PCE could be further enhanced by insertion of auxiliary acceptor groups (Benzothiadiazole, Quinoline derivatives, etc.), and co-sensitization process, which is under investigation in our group.

\section{Supporting Information}

Characterization data of the compounds such as ${ }^{1} \mathrm{H}$ NMR (Figures S1, S3, S5, S7, S9, S11, S13, S15, S17 and S19), LC-MS and MALDI-MS spectra (Figures S2, S4, S6, S8, S10, S12, S14, S16, S18 and S20), theoretical absorption spectra (Figure S19), fluorescence behaviour (Figure S20), Singlet excited-state lifetimes (Figure S21), Optimized structure of dyes (Figure S22), Oxidative OTTLE studies (Figure S28), Photocurrent action spectra porphyrin sensitizers using different concentrations of 4-tert butylpyridine (Figure S23), Current-voltage characteristics of porphyrin sensitizers using different concentrations of 4tert butylpyridine (Figure S24) and TG/DTG (Figure S25), are available free of charge via the Internet at http://pubs.acs.org.

\section{Acknowledgements}

We thank CSIR-NISE, the Department of Science \& Technology (DST), and the Government of India under the major project DST-UK ('APEX-II') and DST-SERI for the financial support to carry out this work. NVK and JVSK thanks to CSIR and UGC for research fellowship. A. Islam acknowledges the support of the JSPS KAKENHI grant No. 26288113. I. Bedja extends his appreciation to the Deanship of Scientific Research at King Saud University for funding this work through research group NO (RG-1438-041).

\section{References and notes}

1. Ibb-Mohammed, T.; Koh, S. C. L.; Raney, I. M.; Acquaye, A.; Schileo, G.; Mustapha, K. B.; Greenough, R. Perovksite solar cells: An integrated hybrid lifecycle assessment and review in comparison with other photovoltaic technologies. Renewable \& Sustainable Energy Rev. 2017, 80, 1321-1344. 
2. Bella, F.; Galliano, S.; Falco, M.; Viscardi, G.; Barolo, C.; Grätzel, M. ; Gerbaldi, C. Unveiling iodine-based electrolytes chemistry in aqueous dye-sensitized solar cells. Chem. Sci. 2016, 7, 4880-4890.

3. Huang, Z. -S.; Meier, H.; Cao, D. Phenothiazine-based dyes for efficient dyesensitized solar cells. J. Mate. Chem. C. 2016, 4, 2404-2426.

4. Ye, M.; Wen, X.; Wang, M.; Iocozzia, J.; Zhang, N.; Lin, C.; Lin. Z. Recent advances in dye-sensitized solar cells: from photoanodes, sensitizers and electrolytes to counter electrodes. Materials Today 2015, 18, 155-162.

5. Higashino, T.; Imahori, H. Porphyrins as excellent dyes for dye-sensitized solar cells: recent developments and insights. Dalton Trans. 2015, 44, 448-463.

6. Giribabu, L.; Bolligarla, R.; Panigrahi, M. Recent Advances of Cobalt (II/III) Redox Couples for Dye-Sensitized Solar Cell Applications. Chem. Rec. 2015, 15, 760-788.

7. Zhang, S.; Yang, X.; Numata, Y.; Han, L. Highly efficient dye-sensitized solar cells: progress and future challenges. Energy Environ. Sci. 2013, 6, 1443-1464.

8. Han, L.; Islam, A.; Chem, H.; Chandrasekharam, M.; Chiranjeevi, B.; Zhang, S.; Wang, X.; Yanagada, M. High-efficiency Dye-Sensitized Solar Cell with a Novel Coadsorbent. Energy Evinorn. Sci., 2012, 5, 6057-6060.

9. Giribabu, L.; Kanaparthi, R. K.; Velkannan,V. Molecular engineering of sensitizers for dye-sensitized solar cell applications. Chem. Rec. 2012, 12, 306-328.

10. Grätzel, M. Recent advances in sensitized mesoscopic solar cells. Acc. Chem. Res. 2009, 42, 1788-1798.

11. Jella, T.; Srikanth, M.; Bolligarla, R.; Soujanya, Y.; Singh, S.P.; Giribabu, L. Benzimidazole-functionalized ancillary ligands for heteroleptic $\mathrm{Ru}(\mathrm{II})$ complexes: synthesis, characterization and dye-sensitized solar cell applications. Dalton Trans. 2015, 44, 14697-14706.

12. Giribabu, L.; Bessho, T.; Srinivasu, M.; Vijaykumar, Ch.; Soujanya, Y.; Reddy, V.G.; Reddy, P.Y.; Yum, J.-H.; Grätzel, M.; Nazeeruddin, M.K. A new familiy of heteroleptic ruthenium (ii) polypyridyl complexes for sensitization of nanocrystalline $\mathrm{TiO}_{2}$ films. Dalton Trans. 2011, 40, 4497-4504.

13. Han, L.; Islam, A.; Chen, H.; Chandrasekharam, M.; Chiranjeevi, B.; Zhang, S.; Yang, X.; Yanagida, M. High-efficiency dye-sensitized solar cell with a novel coadsorbent. Energy Environ. Sci. 2012, 5, 6057-6060.

14. Nazeeruddin, M.K.; Pechy, P.; Renouard, T.; Zakeeruddin, S.M.; Humphry-Baker, R.; Comte, P.; Liska, P.; Cevery, L.; Costa, E.; Shklover, V.; Spiccia, L.; Deacon, G.B.; Bignozzi, C.A.; Grätzel, M. Engineering of efficient panchromatic sensitizers for nanocrystalline TiO2-based solar cells. J. Am. Chem. Soc. 2001, 123, 1613-1624.

15. O'Regan, B.; Grätzel, M. A low-cost, high-efficiency solar cell based on dyesensitized. Nature 1991, 353, 737-740. 
16. Lo , C Y.; Kumar, D; Chou, S H.; Chen, C H.;Tsa,i C H.; Liu ,S H.; Chou, P T.; and Wong, K T. Highly Twisted Dianchoring D- $\pi-A$ Sensitizers for Efficient DyeSensitized Solar Cells. Appl. Mater. Interfaces 2016, 8, 27832-27842.

17. Reeta, P. S.; Giribabu, L.; Senthilarasu, S.; Hsu, M. -H.; Kumar, D. K.; Upadhyaya, H. M.; Robertson, N.; Hewat, T. Ethynyl Thiophene-Appended Unsymmetrical Zinc Porphyrin Sensitizers for Dye-Sensitized Solar Cells. RSC Adv., 2014, 4, 1416514175.

18. Fischer, M K R.; Wenger, S.; Wang, M.; Mishra A.; Zakeeruddin, S M.; Michael Grätzel, M.; and Bäuerle, P. D- $\pi$-A Sensitizers for Dye-Sensitized Solar Cells: Linear vs Branched Oligothiophenes. Chem. Mater. 2010, 22, 1836-1845.

19. Giribabu, L.; Kanaparthi, R. K. Are porphyrins are alternative to ruthenium(II) sensitizers for dye-sensitized solar cells? Current Sci., 2013, 104, 847-855.

20. Urbani, M.; Grätzel, M.; Nazeeruddin, M. K.; Torres, T. Meso-substituted porphyrins for dye-sensitized solar cells. Chem. Rev. 2014, 114, 12330-12396.

21. Mathew, S.; Yella, A.; Gao, P.; Humphry-Baker, R.; Cur-chod, B. F. E.; AshariAstani, N.; Tavernelli, I.; Rothlis-berger, U.; Nazeeruddin, M. K.; Grätzel, M. Dyesensitized solar cells with $13 \%$ efficiency achieved through the molecular engineering of porphyrin sensitizers. Nature Chem. 2014, 6, 242-247.

22. Krishna, N V.; Krishna, J V S.; Singh, S P.; Giribabu, L.; Han, Li.; Bedja, I.; Gupta, R K.; and Islam, A., Donor- $\pi-$ Acceptor Based Stable Porphyrin Sensitizers for Dye Sensitized Solar Cells: Effect of $\pi$-Conjugated Spacers. J. Phys. Chem C. 2017, 121 , 6464-6477.

23. Yen, Y. S.; Ni, J. S.; Lin, T. Y.; Hung, W. I.; Lin, J. T.; Yeh, M. C. P. Imidazole Based Sensitizers Containing Double Anchors for Dye Sensitized Solar Cells. E. J. Org. Chem. 2015, 33, 7367-7377.

24. Skonieczny, K.; Gryko, D. T. Photochemical Conversion of Phenanthro[9,10d]imidazoles into $\pi$-Expanded Heterocycles, J. Org. Chem. 2015, 80, 5753-5763.

25. Sanchis, T. R.; Guo, B.; Wu, H. P.; Pan, T. Y.; Lee, H. W.; Raga, S. R.; Santiago, F. F.; Bisquert, J.; Yeh, C. -Y.; Diau, E. W. -G. Design and characterization of alkoxywrapped push-pull porphyrins for dye-sensitized solar cells. Chem. Commun. 2012, 48, 4368-4370.

26. Hai-Lang, J.; Zhang, M. -D.; Ju, Z. -M.; Zheng, H. -G.; Ju, X. -H. Picolinic acid as an efficient tridentate anchoring group adsorbing at Lewis acid sites and Brønsted acid sites of the $\mathrm{TiO} 2$ surface in dye-sensitized solar cells. J. Mater. Chem. A 2015, 3, 14809-14816.

27. Yella, A.; Lee, H.W.; Tsao, H. N.; Yi, C.; Chandiran, A. K.; Nazeeruddin, M. K.; Diau, E.W. G.; Yeh, C. Y.; Zakeeruddin, S. M.; Grätzel, M. Porphyrin-sensitized solar cells with cobalt (II/III)-based redox electrolyte exceed 12 percent efficiency. Science 2011, 334, 629. 
28. Zhang, S.; Islam, A.; Yang, X.; Qin, Ch.; Zhang, K.; Numata, Y.; Chen, H.; Han, L. Improvement of Spectra Reponse by Co-Sensitizers for High Efficiency DyeSensitized Solar Cells. J. Mate. Chem. A 2013, 1, 4812-4819.

29. Pomogailo A. D.; Razumov V. F,; Voloshanovskii I. S. Synthesis and Structure of Vinylporphyrin Metal Complexes and their Copolymerization: Spectral, Luminescence Properties of $\mathrm{Zn}$ Copolymers in Solution. J. Porphyrins Phthalocyanines 2000; 4, 45-64.

30. Becke, A. D. Density-functional thermochemistry. III. The role of exact exchange. $J$. Chem. Phys. 1993, 98, 5648-5652.

31. Peterson, G. A.; Al-Laham, M. A. A complete basis set model chemistry. II. Open-shell systems and the total energies of the first-row atoms. J. Chem. Phys. 1991, 94, 6081-6090.

32. Gaussian 09, Frisch, M. J.; Trucks, G. W.; Schlegel, H. B.; Scuseria, G. E.; Robb, M.; Cheeseman, A.J. R.; Zakrzewski, V. G.; Montgomery, J. A.; Stratmann, R. E.; Burant, J. C.; Dapprich, S.; Millam, J. M.; Daniels, A. D.; Kudin, K. N.; Strain, M. C.; Farkas, O.; et al. Gaussian, Inc., Pittsburgh PA, 2009.

33. Miertus, S.; Scrocco, E.; Tomasi, J. Electrostatic interaction of a solute with a continuum. A direct utilizaion of $\mathrm{AB}$ initio molecular potentials for the prevision of solvent effects. J. Chem. Phys. 1981, 55, 117-129.

34. Cossi, M.; Barone, V.; Cammi, R.; Tomasi, J. Ab initio study of solvated molecules: a new implementation of the polarizable continuum model. Chem. Phys. Lett. 1996, 255, 327-335.

35. O'Boyle, N. M.; Tenderholt, A. L.; Langner, K. M. Cclib: a library for package-independent computational chemistry algorithms. J. Comput. Chem. 2008, 29, 839-845.

36. Dennington, R.; Keith T.; Millam, J. GaussView, version 5, Semichem Inc., Shawnee Mission KS, 2009.

37. Giribabu, L.; Duvva, N.; Singh, S.P.; Han, L.; Bedja, I.M.; Gupta, R.K.; Islam, A. Stable and charge recombination minimized $\pi$-extended thioalkyl substituted tetrathiafulvalene dye-sensitized solar cells. Mater. Chem. Front. 2017, 1, 460-467.

38. Giribabu, L.; Duvva, N.; Prasanthkumar, S.; Singh, S. P.; Han, L.; Bedja, I.; Gupta, R. $\mathrm{K}$; Islam, A. Effect of spacers and anchoring groups of extended $\pi$-conjugated Tetrathiafulvalene based Sensitizers on the Performance of Dye-Sensitized Solar Cells. Sustainable Energy \& Fuels 2017, 1, 345-353.

39. Sonogashira, K. Development of $\mathrm{Pd}-\mathrm{Cu}$ catalyzed cross-coupling of terminal acetylenes with sp 2-carbon halides. J. Organomet. Chem. 2002, 653, 46-49.

40. Shahroosvand, H.; Zakavi, S.; Sousaraeia, A.; Eskandaria, M. Saddle-shaped porphyrins for dye-sensitized solar cells: new insight into the relationship between nonplanarity and photovoltaic properties. Phys. Chem. Chem. Phys. 2015, 17, 63476358. 
41. Rochford, J.; Galoppini, E. Zinc (II) Tetra Aryl Porphyrins Anchored to TiO2, ZnO and $\mathrm{ZrO}_{2}$ Nanoparticle Films through Rigid Rod Linkers. Langmuir 2008, 24, 53665374.

42. Liu, Y.; Xian, N.; Feng, P.; Shen, P.; Zhou, W.; Weng, C.; Zhao, B. Tan, S. Thiophene-linked Porphyrin Derivatives for Dye-Sensitized Solar Cells. Chem. Commun., 2009, 2499-2501.

43. Hagfeldt, A.; Grätzel, M. Light-induced redox reactions in nanocrystalline systems. Chem. Rev. 1995, 95, 49-68.

44. Monti, A.; de Groot, H. J. M.; Buda, F. In-silico Design of a Donor-Antenna-Acceptor Supramolecular Complex for Photoinduced Charge Separation. J. Phys. Chem. C 2014, 118, 15600-15609.

45. Delcamp, J. H.; Shi, Y.; Yum, J. H.; Sajoto, T.; Dell'Orto, E.; Barlow, S.; Grätzel, M. The Role of $\pi$ Bridges in High Efficiency DSCs Based on Unsymmetrical Squaraines. Chem. Eur. J. 2013, 19, 1819-1827.

46. A. Hagfeldt, G. Boschloo, L. Sun, L. Kloo and H. Pettersson. Dye-Sensitized Solar Cells. Chem. Rev., 2010, 110, 6595-6663.

47. S. Pelet, J.-E. Moser and M. Grätzel. Cooperative Effect of Adsorbed Cations and Iodide on the Interception of Back Electron Transfer in the Dye Sensitization of Nanocrystalline $\mathrm{TiO}_{2}$. J. Phys. Chem. B, 2000, 104, 1791-1795.

48. G. Boschloo and A. Hagfeldt, Photoinduced absorption spectroscopy of dyesensitized nanostructured $\mathrm{TiO}_{2}$. Chemi. Phys. Lett., 2003, 370, 381-386.

49. H. Nusbaumer, J.-E. Moser, S. M. Zakeeruddin, M. K. Nazeeruddin and M. Grätzel. CoII(dbbip $)_{2}{ }^{2+}$ Complex Rivals Tri-iodide/Iodide Redox Mediator in Dye-Sensitized Photovoltaic Cells. J. Phys. Chem. B, 2001, 105, 10461-10464.

50. Ellis, H.; Schmidt, I.; Hagfeldt, A.; Wittstock, G.; Boschloo, G. Influence of Dye Architecture of Triphenylamine Based Organic Dyes on the Kinetics in DyeSensitized Solar Cells. J. Phys. Chem. C 2015, 119, 21775-21783

51. G. Boschloo and A. Hagfeldt. Characteristics of the Iodide/Triiodide Redox Mediator in Dye-Sensitized Solar Cells. Accounts chem. Res. 2009, 42, 1819-1826.

52. Torben Daeneke, Attila J. Mozer, Yu Uemura, Satoshi Makuta, Monika Fekete, Yasuhiro Tachibana, Nagatoshi Koumura, Udo Bach, and Leone Spiccia, J. Am. Chem. Soc. 2012, 134, 16925-16928.

53. Wei, X.; Du, X.; Chen, D.; Chen, Z. Thermal Analysis Study of 5,10,15,20-tetrakis (methoxypheny) Porphyrins and their Nickel Complexes. Thermochim. Acta 2006, $440,181-187$. 


\section{Bulky Nature Phenanthroimidazole based Donors in Porphyrin Sensitizers for DSSC Applications.}

Narra Vamsi Krishna*, Jonnadula Venkata Suman Krishna ${ }^{* *}$, Surya Prakash Singh" Lingamallu Giribabu**, Ashraful Islam, Idriss Bedjal.

* Inorganic \& Physical Chemistry Division, CSIR-Indian Institute of Chemical Technology, Tarnaka, Hyderabad-500007, India.

*Academy of Scientific and Innovative Research, CSIR-Indian Institute of Chemical Technology, India.

§ Photovoltaic Materials Unit, National Institute for Materials Science, Sengen 1-2-1, Tsukuba, Ibaraki $305-$ 0047, Japan.

"Cornea Research Chair, Department of Optometry, College of Applied Medical Sciences, King Saud University, Riyadh 11433, Saudi Arabia.

Corresponding authors: giribabu@iict.res.in, Phone: +91-40-27191724, Fax: +91-40-27160921;

Islam.Ashraful@nims.go.jp,

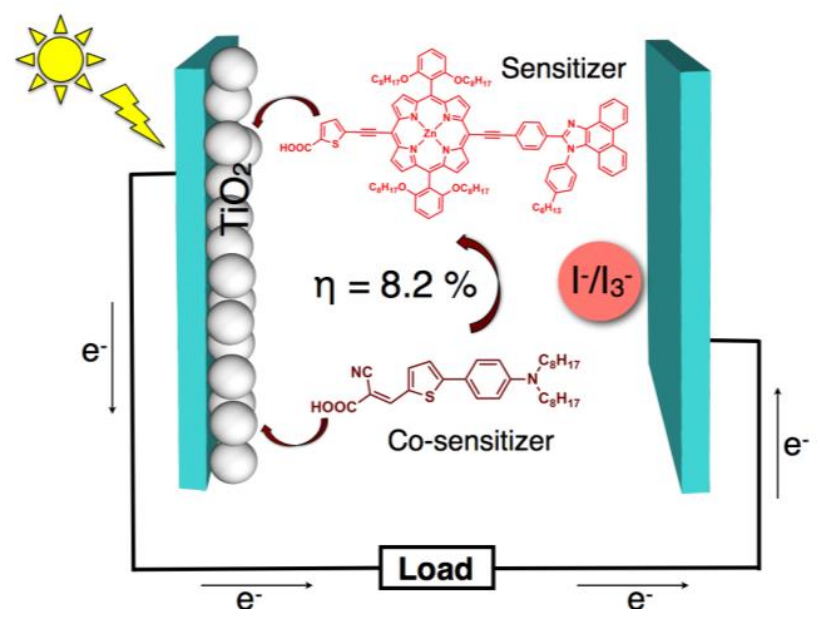

